\title{
Sensitivity to Energy Technology Costs: A Multi-model comparison analysis
}

Valentina Bosetti*,1, Giacomo Marangoni ${ }^{1,2}$, Emanuele Borgonovo*, Laura Diaz Anadon ${ }^{3}$, Robert Barron ${ }^{4}$, Haewon C. McJeon ${ }^{5}$, Savvas Politis ${ }^{6}$, Paul Friley ${ }^{6}$

*Bocconi University, Italy

${ }^{1}$ Fondazione Eni Enrico Mattei, Milano and CMCC, Italy

${ }^{2}$ Politecnico di Milano, Italy

${ }^{3}$ Harvard Kennedy School, Harvard University, Cambridge, MA, USA

${ }^{4}$ University of Massachusetts Amherst, Amherst, Massachusetts, USA

${ }^{5}$ Pacific Northwest National Laboratory, JGCRI, College Park, MD, USA

${ }^{6}$ Brookhaven National Laboratory, USA

\begin{abstract}
In the present paper we use the output of multiple expert elicitation surveys on the future cost of key low-carbon technologies and use it as input of three Integrated Assessment models, GCAM, MARKAL_US and WITCH. By means of a large set of simulations we aim to assess the implications of these subjective distributions of technological costs over key model outputs. We are able to detect what sources of technology uncertainty are more influential, how this differs across models, and whether and how results are affected by the time horizon, the metric considered or the stringency of the climate policy. In unconstrained emission scenarios, within the range of future technology performances considered in the present analysis, the cost of nuclear energy is shown to dominate all others in affecting future emissions. Climate-constrained scenarios, stress the relevance, in addition to that of nuclear energy, of biofuels, as they represent the main source of decarbonization of the transportation sector and bioenergy, since the latter can be coupled with Carbon Capture and Storage (CCS) to produce negative emissions.
\end{abstract}

Keywords: Sensitivity Analysis, Integrated Assessment models, Expert elicitation, Technology Cost

\section{Introduction}

Future costs of low-carbon technological options are a key factor in determining climate policy costs and

feasibility. The recent Fifth Assessment report of the IPCC WG III (IPCC, 2014) stresses the relevance of

assumptions concerning the availability and costs of future technologies in shaping the range of policy costs.

This has long been recognized within the Integrated Assessment modeling (IAM) community (Edmonds et al.,

2012), and the quantitative analysis of the future availability/cost of carbon-free and low-carbon technologies

has been at the center of a growing literature. The most commonly adopted approach relies on the use of an IAM 
and the running of climate-constrained scenarios with and without the availability of key energy technologies, in order to assess the increase in climate mitigation costs/carbon prices under each alternative. A few studies have comprehensively analyzed the impact of advances in future energy technologies on the cost of greenhouse gas mitigation by means of sensitivity analysis and using an individual model (McJeon et al. 2011; Lemoine and McJeon, 2013; Rogelj et al. 2012, Anadón et al. 2014.). In parallel to these pioneering works, a set of modeling comparison analyses has been performed. We recall the Energy Modelling Forum (EMF) 27 (Kriegler, 2014) and the Assessment of Climate Change Mitigation Pathways and Evaluation of the Robustness of Mitigation Cost Estimates (AMPERE) Project (Riahi, 2013). The latter studies are characterized by selected sensitivity analyses to extreme technology realizations and a focus on robust results across models. The findings that emerged from these and other studies, as summarized in the IPCC latest assessment report (IPCC, 2014) are that: (a) Carbon Dioxide Removal (CDR) technologies, which can be used to generate negative emissions, are the most critical class of technologies, as they allow a modification in the time path of the emissions constraint (the possibility of negative emissions by the end of the century would allow postponing peak emissions later in the century); (b) bioenergy coupled with CCS would have a central role, and the unavailability of either component of this technology would result in an increase in policy costs between $18 \%$ and $300 \%$, depending on the stringency of the climate scenario analyzed and whether the limitation of technology availability concerns bioenergy or CCS. Assumptions about the availability of other low-carbon energy technologies also matter (for 
example, the availability of low-cost renewables, CCS alone, and nuclear power), although their impact on mitigation costs are typically less pronounced.

In this study, by building on this existing knowledge, we use a different approach to evaluate the extent to which uncertainty about future technology costs in key energy technologies translates to different model outcomes. Instead of switching on and off one technology at a time (or in combination) in various models, we explore the space of future technological costs and other parameters, parameterized by using a set of expert elicitation surveys. In particular, we take stock of extensive efforts that have been carried out independently by researchers at UMass Amherst (Baker \& Keisler, Cellulosic biofuels Expert views on prospects for advancement, 2011; Baker, Chon, \& Keisler, Advanced solar R\&D: Combining economic analysis with expert elicitations to inform climate policy, 2009b; Baker, Chon, \& Keisler, Carbon capture and storage: combining economic analysis with expert elicitations to inform climate policy, 2009a; Baker, Chon, \& Keisler, Advanced Nuclear Power: Combining Economic Analysis with Expert Elicitations to Inform Climate Policy, 2008), Harvard (Anadon, et al., 2011; Anadon, Bosetti, Bunn, Catenacci, \& Lee, 2012; Anadón, Chan, \& Lee, 2014a; Chan, Anadón, Chan, \& Lee, 2011), and FEEM (Bosetti, Catenacci, Fiorese, \& Verdolini, 2012; Catenacci, Bosetti, \& Fiorese, 2013; Fiorese, Catenacci, Verdolini, \& Bosetti, 2013). Each of these groups collected the opinions of leading experts from the academic world, the private sector, and international institutions on the probabilistic distribution of future costs of the most promising clean energy technologies, conditionally to different levels of 
R\&D efforts. The technologies include liquid biofuels, electricity from biomass, carbon capture (CCS), nuclear power, and solar photovoltaic (PV) power. All surveys were carried out by means of structured protocols aiming at minimizing potential biases and overconfidence that can characterized experts elicitations(Morgan, 2014). Although different groups carried out surveys covering the same set of technologies, each group worked independently, and thus asked questions using different formats, looking at different endpoints and cost metrics. Therefore, the effort of harmonizing the data across surveys has represented a complex endeavor which is fully described in Baker et al. (2014a). The resulting estimates span a wide array of uncertainties including those that might be related to different methodology employed to collect the data from experts.

By using this data we can explore differences in the sensitivity of various models to parameter uncertainty as expressed by a vast collection of recently elicited subjective expert judgments.

This is important per se, as it permits us to systematically explore the technological cost dimension as defined by experts (rather than only exploring the extremes of the cost space). In order to do so, we employ a combination of global sensitivity measurements and estimation methods that allow us to address in depth key questions about the behavior of the alternative models. In particular, we obtain quantitative insights about whether keyuncertainty drivers are the same across models and whether this is robust across alternative output of models (as for example cumulative emissions or technology penetration). 
Aside the modeling insights, this analysis is also an essential step toward the design of optimal energy R\&D portfolios as described in (Baker et al. 2014b), because it improves our understanding of the extent to which technology assumptions drive results as well as of what other parameters affect differences across models.

This paper is structured as follows: the next section provides a general overview of the experimental protocol and the methodology used to assess the sensitivity of the models, and in addition it introduces the integrated assessment models used and the ways in which they have been modified to incorporate the information coming from the expert elicitation surveys. Section 3 presents the main sensitivity results, while Section 4 states our conclusions.

\section{Methods}

Our objective is to assess the implications of changes in the future costs and performance parameters of a few key energy technologies in relation to important macro-economic and global environmental metrics. We set out using as an input to integrated assessment models the results from the aggregated expert elicitations data described in (Baker et al, 2014a).

In this section we present methodological details on the technology input specifications, the sampling strategy, the models used, the explored climate policy scenarios, and the metrics adopted for the evaluation of the sensitivity across models and technologies. 


\subsection{Technology input specifications}

In the present analysis we focus our attention on the following technologies (and metrics): solar power (levelized cost of electricity), nuclear power (overnight capital cost), biofuels (cost and conversion efficiency), bioelectricity (cost and conversion efficiency) and carbon capture and storage (CCS) (capital cost and energy penalty). By harmonizing and aggregating the data across experts and across surveys by means of the process described in (Baker, 2014a), we obtain eight probability distributions representing the values of these uncertain metrics (summary statistics for the distributions are reported in Table 1). We generate 740 scenarios, representing combinations of technology performances drawn from these eight cost distributions. Each model is then set up to implement the assumptions of the 740 scenarios.

Table 1. Importance Sampling Distributions

\begin{tabular}{lllrrrrr}
\hline Quantities & Distribution & Units & \multicolumn{1}{c}{ Min } & Median & Max & Mean & St. dev \\
\hline Solar LCOE & LogUniform & \$/KWh & 0.02 & 0.09 & 0.45 & 0.14 & 0.12 \\
Nuclear & LogUniform & \$/KW & 385 & 1534 & 5728 & 2017 & 1489 \\
Biofuels cost & LogUniform & \$/GGE & 0.22 & 1.57 & 10.56 & 2.56 & 2.54 \\
Biofuels efficiency & Uniform & $\%$ & 19 & 52 & 85 & 52 & 19 \\
Bio-electricity cost & LogUniform & \$/KWh & 0.01 & 0.04 & 0.23 & 0.06 & 0.06 \\
Bio-electricity efficiency & Uniform & $\%$ & 7 & 47 & 85 & 47 & 22 \\
CCS cost & Uniform & \$/KW & 5 & 2019 & 3920 & 2006 & 1142 \\
CCS energy penalty & Uniform & $\%$ & 0 & 22 & 43 & 22 & 12 \\
\hline
\end{tabular}

\subsection{Sampling method to define model runs and policy scenarios}

Instead of sampling the cost or parameter values space by means of an equally distanced sample, we use importance sampling (Glynn and Iglehart, 1989). Importance sampling has generally been used as a version of 
Monte Carlo-type analysis, when the area of interest in the distributions of cost and performance has a very low probability. In our case this is relevant because, for example, very low nuclear costs (which are also associated with low probabilities of occurrence) are expected to have a large impact on societal and environmental outcomes in the models, in particular in climate constrained scenarios which are at the heart of our analysis. In other words, if we had sampled randomly, we might not have had enough runs covering the part of the technology cost distribution of interest. ${ }^{1}$

Each of the 740 runs is repeated for three policy scenarios: a baseline scenario where no climate policy is in place, and two climate policy scenarios where global emissions (US emissions for MARKAL-US) are constrained. The two constrained scenarios are in line with two of the four representative concentration pathways (RCPs) developed for the modeling experiments of the climate modeling community and spanning the range of radiative forcing values ${ }^{2}$ for the year 2100 from 2.6 to $8.5 \mathrm{~W} / \mathrm{m} 2$ (International Institute for Applied Systems Analysis 2009, RCP Database). In particular, models run with emissions caps in line with scenarios imposing a radiative forcing of 2.6 and $4.5 \mathrm{~W} / \mathrm{m} 2$ by 2100 . In our experiment when-flexibility on emission reduction is not allowed, that is, the constraint on emissions is not only on the carbon budget but also on the emissions time

\footnotetext{
${ }^{1}$ Importance sampling allows us to sample from a different distribution, and renormalize back to the actual distribution of interest. We use it here as in the portfolio analysis discussed in Baker et al. 2014b to limit the number of times we ran the three IAMs. Since we have four alternative distributions of technology costs and performance (one for each of the teams that conducted the elicitations-UMass, FEEM and Harvard - plus the combined distribution) and three to five possible $R \& D$ portfolios (as we consider three levels of $R \& D$ for each of the five technologies, the number of runs needed to capture the impact of technology uncertainty on model outputs in the IAMs would have been exceedingly large. Thus, we defined an "importance distribution" that defined the IAM runs. There is only one importance distribution, rather than 4 (for each team) * 35 (for each possible R\&D portfolio).

${ }^{2}$ When reporting radiative forcing values, it is assumed that they include the forcing of greenhouse gases and other forcing agents, but do not include direct impacts of land use (albedo) or the forcing of mineral dust.
} 
profile (this allows greater comparability across models). The cap on emissions is however global and can be efficiently allocated across countries, except for MARKAL-US, where the cap is for the US only and is derived by the emission cap obtained for the US from the GCAM model. Each of the runs assumes immediate learning: i.e. full anticipation of the realization of technology costs/parameters in 2030 between 2010 and 2030. For the subsequent years we assume that additional learning will take place, but for each run this additional learning will be a function of the actual realization of the parameter and the assumed maximum learning rate, $\beta$, following the asymptotic rule below:

$x_{(i, t)}=x_{(i, 2005)}+\frac{x_{i, t^{\prime}}-x_{i, 2005}}{1-\beta}+\left(1-\beta^{\frac{t-2005}{t^{\prime}-t}}\right)$

where $x_{i, t}$ is the cost (or efficiency level) for technology $\mathrm{i}$ at time $\mathrm{t}, \mathrm{t}$ ' is the period for which information on cost/efficiency was elicited (namely 2030) and $\beta$ is the maximum additional technological change beyond t', which we assume to be $20 \%$ (i.e., $80 \%$ of cost reduction occurs before 2030 and is in accordance with the realization from the elicited distribution. The remainder of $20 \%$ cost reduction occurs after 2030). In addition, we assume that the evolution of cost and performance parameters after 2030 is capped by a floor (ceiling) value for cost (efficiency) which is the minimum (maximum) provided with the sampling statistics. 


\subsection{Description of models and implementation}

We assess the implications of the judgments of experts on the future cost of key energy technologies by using three integrated assessment models: GCAM, MARKAL-US and WITCH.

The difference between the three models can be clustered in two groups:

1) Structural differences: i.e. WITCH and MARKAL_US are solve through intertemporal optimization with perfect foresight; GCAM is a recursive dynamic simulation model. WITCH aggregates technologies via a constant elasticity of substitution functions, whereas in GCAM the aggregation is linear but the cost of technologies has a logistic distribution; system integration and flexibility is modelled in different ways in the three models considered. GCAM and MARKAL-US are more detailed in their descriptions of technologies, while WITCH describes in greater detail the macro-economy component; MARKAL-US describes the US, while GCAM and WITCH have a global coverage.

2) Parametrical: future costs and performance of technologies varies across models, as parameters controlling for technology adoption. Some of these key parameters were varied in a uniform way as an input to each simulations, but other parameters exist and influence the dynamics of the models in different way (an example could be the cost of capital or the cost of nuclear waste management). 
We did our best to harmonize the second source of variation (see the Appendix) in order to emphasize as much as possible the implication of the first source of variation (as an example the assumptions on nuclear waste management cost in WITCH were moderated in order to be comparable with those in GCAM).

However, the distinction between sources of difference in the first and second group is not as clear cut as one might like and differences across models' results presented later will certainly include part of both.

These differences are key to the main purpose of this paper, namely that of assessing the robustness of findings with respect to different model specifications. The research groups involved in this work performed a thorough comparison of the models. In the Appendix we provide the synthesizing result of this comparison effort. Because of the existing structural differences, implementation of the sampling strategy had to be model specific. Details on how costs and efficiency parameters were implemented are also provided at the end of each model description in the Appendix.

\subsection{Comparison methodology and sensitivity methods}

Each of the 740 model runs carried out for the various technology cost combinations constitute an uncertainty analysis (Helton, 1993). Thus, from the corresponding model input-output datasets it is possible to obtain an examination of the statistical properties of the output distribution. The analyst then obtains an indication about how much variability in the output of each model is induced by uncertainty in the same model inputs. 
To augment these insights, we make use of the post-processing or given data logic (Lewandowski, Cooke, \& Duintjer Tebbens, 2007; Elmar Plischke, Borgonovo, \& Smith, 2013). This type of approach to sensitivity analysis uses the results of Monte Carlo simulations to extract additional information that can help the analyst to obtain additional insights about the input-output mapping. In particular, we inspect the following two insights (Anderson, Borgonovo, Galeotti, \& Roson, 2014):

1) Key-uncertainty drivers

2) Sign of change

In sensitivity analysis jargon, these two types of insights are referred to as "sensitivity settings" (Andrea Saltelli, 2002). In our case, the methods used to investigate the two families of questions above need to be probabilistic because we not only are testing for deterministic changes of parameters' values but we have subjective probabilistic information about these parameters. As regards the key-uncertainty drivers setting, we use global sensitivity methods (Emanuele Borgonovo, 2006; A Saltelli et al., 2008). The setup is as follows. The relationship that binds the model inputs (x) to the model output (y) is regarded as a generic mapping of the form

$$
y=g(\mathbf{x}), g: \Omega_{\mathbf{x}} \rightarrow \mathbb{R}
$$

with $\Omega_{\mathbf{x}} \subseteq \mathbb{R}^{k}$ and $k$ denoting the number of model inputs. To illustrate, in our case, we have $\mathrm{k}=8, \Omega_{\mathbf{x}}$ is Cartesian product of the eight ranges displayed in Table 1, $\mathrm{g}$ is the input-output mapping in WITCH, GCAM and MARKAL_US. 
Evaluation of key-uncertainty drivers

As for the key-uncertainty drivers setting, we adopt the three global sensitivity measures synthetically illustrated in Table 2 [for a more detailed overviews the reader is referred to (Anderson et al., 2014; A Saltelli, Ratto,

Tarantola, \& Campolongo, 2005)].

Table 2: Sensitivity measures used in this work for the identification of key-drivers

\begin{tabular}{|l|l|}
\hline Sensitivity Measure & Equation \\
\hline Variance-Based & $\eta_{i}=\frac{V\left[\mathbb{E}\left(Y \mid x_{i}\right)\right]}{V[Y]}=\frac{V[Y]-\mathbb{E}\left[V\left[Y \mid x_{i}\right]\right]}{V[Y]}$ \\
\hline Density-Based & $\delta_{i}=\frac{1}{2} \mathbb{E}\left[\int_{\Omega_{Y}}\left|f_{Y}(y)-f_{Y \mid X_{i}}(y)\right| d y\right]$ \\
\hline CDF-based & $\beta_{i}^{K U}=\mathbb{E}\left\{\sup _{y}\left|F_{Y}(y)-F_{\left(Y \mid \mathrm{X}_{i}=x_{i}\right)}(y)\right|+\sup _{y}\left|F_{\left(Y \mid \mathrm{X}_{i}=x_{i}\right)}(y)-F_{Y}(y)\right|\right\}$, \\
\hline
\end{tabular}

These sensitivity measures are statistics of the form (E Borgonovo, Hazen, \& Plischke, 2014):

$$
\xi_{i}=\mathbb{E}\left[s\left\{F_{Y}(y), F_{Y \mid X_{i}}(y)\right\}\right]
$$

where $s\left\{F_{Y}(y), F_{Y \mid X_{i}=x_{i}}(y)\right\}$ is some form of separation measurement between the unconditional $\left(F_{Y}(y)\right)$ and conditional model output distribution $F_{Y \mid X_{i}=x_{i}}(y)$ [we refer to (Glick, 1975) on the concept of separation measurement]. 
Variance-based sensitivity measures (second row in Table 2) quantify the separation as expected variance reduction. In particular, the sensitivity measure $\eta_{i}$ is Pearson's correlation ratio (Lewandowski et al., 2007; Pearson, 1905). Thus, according to $\eta_{i}$ the most important model input is the one that, when fixed, reduces the model output variance the most. Density-based importance measures (third row in Table 2), identify the most important model input as the one that shifts the model output density the most (E. Borgonovo, 2007). The CDFbased sensitivity measure in the last row of Table 2 quantifies the influence of model input $X_{i}$ through the Kuiper distance on cumulative distribution functions [see (Tygert, 2010) for properties of the Kuiper metrics and (Baucells \& Borgonovo, 2013) for properties of the sensitivity measure in the fourth row of Table 2]. It should be noted that all these sensitivity measures are normalized between zero and unity.

The rationale for using a combination of sensitivity measures is as follows. Each sensitivity measure considers a different property of the model output distribution. Thus, if a model input is deemed irrelevant by all the measures, then we can have greater confidence that its influence is low. Second, each sensitivity measure has limitations. For instance, in using variance based sensitivity measures one is exposed to the risk of deeming a model input uninfluential when, indeed, $\mathrm{Y}$ is dependent on it (see the example in (Elmar Plischke et al., 2013)). Conversely, density and CDF-based sensitivity measures are null if and only if $\mathrm{Y}$ is independent of $X_{i}$, avoiding such risk. 
Evaluation of sign of change

As for sign of change, we rely on the first order effects of the functional ANOVA expansion of the model output.

The rationale is explained in (Anderson et al., 2014), to which we refer for further details and mathematical

aspects. We limit ourselves here to the following observations on the underlying intuition. Assuming that the

multivariate mapping as in eq. (1) is integrable, we can expand it in the form

$$
g(\mathbf{x})=g_{0}+\sum_{i=1}^{n} g_{i}\left(x_{i}\right)+\sum_{i<j}^{n} g_{i, j}\left(x_{i}, x_{j}\right)+\ldots+g_{1,2, \ldots, n}\left(x_{1}, x_{2}, \ldots, x_{n}\right)
$$

where the terms in eq. (3) have the following meaning. $g_{0}$ is the mean value of y. $g_{i}\left(x_{i}\right)$ is individual effect of

$x_{i}$, namely, the expected behavior of $g$ as a function of $x_{i}$ alone. In formulae,

$$
g_{i}\left(x_{i}\right)=\mathbb{E}\left[g(\mathbf{x}) \mid X_{i}=x_{i}\right]-g_{0}=\int \ldots \int g(\mathbf{x}) \prod_{s=1, s \neq i}^{n} d F_{s}-g_{0}
$$

that is, $g_{i}\left(x_{i}\right)$ is the conditional expectation of $\mathrm{g}$ given $\mathrm{x}_{\mathrm{i}}$, from which the mean value of $\mathrm{g}$ is subtracted. Note that in eq. (4) $\mathrm{g}$ is integrated over all variables but $x_{i}$. The second order terms $g_{i, j}\left(x_{i}, x_{j}\right)$ account for the residual effects of the interactions of the corresponding model inputs, and so on. These terms are obtained through conditional expectations followed by proper orthogonalization, see (Rabitz \& Aliş, 1999).

By determining sign of change, we mean a generalization of the comparative statics question of (Samuelson, 1947): it is hoped to formulate qualitative restrictions on slopes, curvatures, ...(Samuelson, 1947). That is, we are interested in studying whether, on average, the variation in a model input leads to an increase or decrease in 
the model output. The literature has ascertained that, under uncertainty, this answer can be gained by considering the first order effects of the functional ANOVA expansion. In fact, it is proven in (Beccacece \& Borgonovo, 2011) that these effects retain the monotonicity of the original input-output mapping. To clarify, if $g$ is increasing in $x_{i}$, then $g_{i}\left(x_{i}\right)$ is increasing, see (Anderson et al., 2014) for further details.

Finally, a note on the estimation. All sensitivity measures and functional ANOVA effects are obtained by using a post-processing logic (Lewandowski et al., 2007). A set of methods has been examined by the authors. For variance-based, we used the COSI method of (E Plischke, 2012) the given-data estimator of (Elmar Plischke et al., 2013), the cut-HDMR estimator of (Ziehn \& Tomlin, 2009), as well as a recent smoothing spline estimation subroutine $^{3}$. For first order effect interpolation, we also used the smoothing spline ANOVA metamodel of (Ratto, Pagano, \& Young, 2007). For density- and CDF-based sensitivity measures, we used the given-data estimators of (Elmar Plischke et al., 2013) and (Baucells \& Borgonovo, 2013).

In the next Section, a selected subset of the numerical results obtained is presented and discussed.

\section{Discussion of Results}

\subsection{Baseline Scenario}

In a baseline scenario, the model output on which it is most interesting to assess the effects of technology performance are fossil fuel emissions. Effects on GDP would also be relevant, as the future cost of energy

\footnotetext{
${ }^{3}$ By W. Becker, personal communication to the authors, and available at http://ipsc.jrc.ec.europa.eu/?id=756.
} 
technologies does affect the pace of growth, but we abstain from this type of analysis as it is not possible to perform it with all three models: GDP does not change in response to technology performance parameters changes in the GCAM model. As MARKAL_US has a US focus, we will compare results from MARKAL_US with those emerging from the WITCH model for the US region.

Figure 1 reports the global (left hand side panel) and US (right hand side panel) emissions spanned by the runs performed with the GCAM and WITCH, MARKAL_US and WITCH (reporting the US region only) models, respectively. In addition, for the sake of comparison, we also report the RCP 2.6 and 4.5 global fossil fuel emissions that we impose on the models for the climate-constrained runs described later.
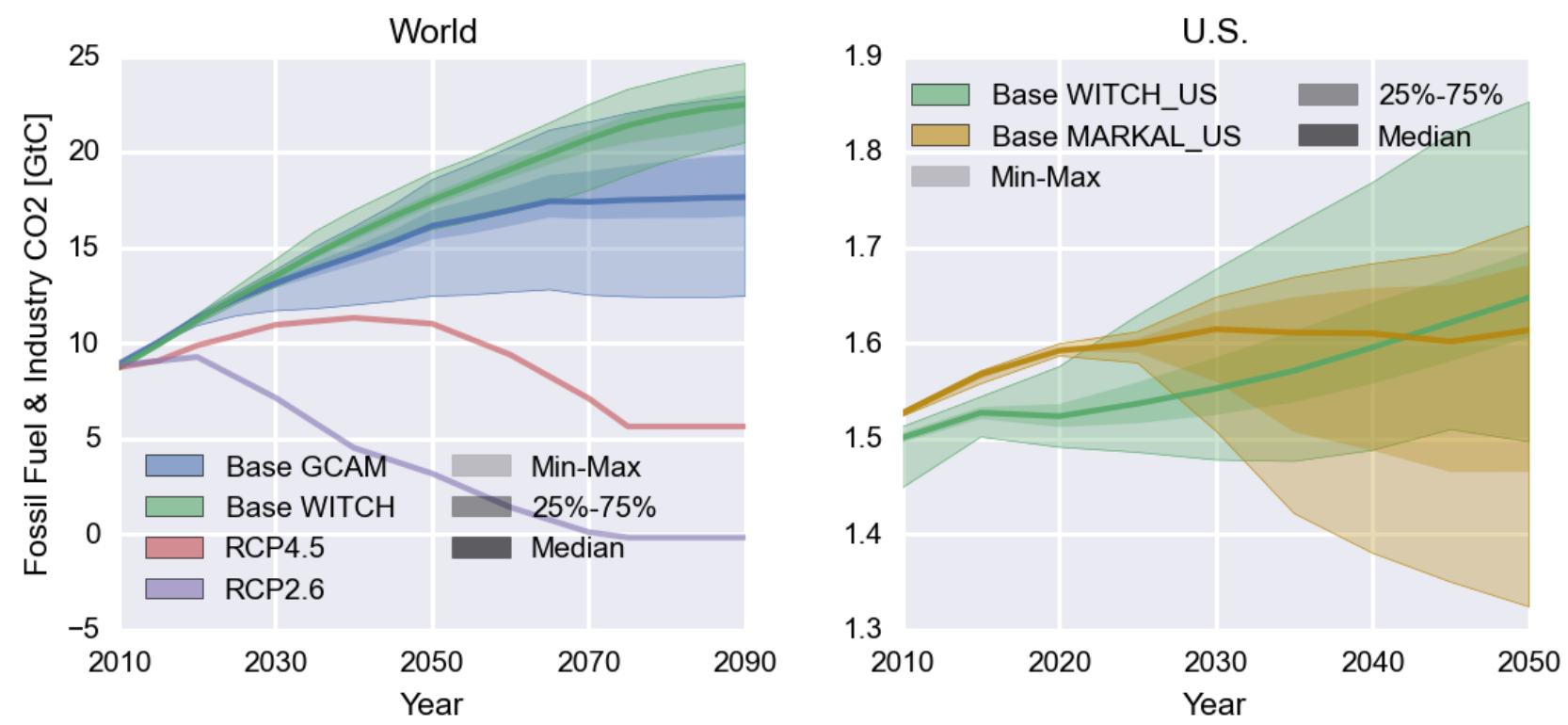

Figure 1: Global (left panel) and US (right panel) carbon dioxide emissions from Fossil Fuel combustion and Industrial processes (FFI). Different colors correspond to different policies, where the light color encompasses the minimum-maximum range, and the darker one encompasses the $\mathbf{2 5 \%}-\mathbf{7 5} \%$ quantiles range. This color convention is adopted throughout the paper in all the timeseries figures. 
When looking at global numbers, it is interesting to note how the GCAM model spans a much wider range of variations in baseline emissions, both at the extreme and for the $25^{\text {th }}-75^{\text {th }}$ percentiles (darker shaded area). In GCAM, for some extreme realizations of cost and efficiency parameters, emissions remain almost at their 2015 levels throughout the century. For some other combinations they double by 2100. Conversely, the WITCH model is much less sensitive to cost and efficiency variations considered in this exercise and, in average, emissions grow more by the end of the century, even under the most optimistic realization of parameters. This difference in the response to energy costs realization, as will be unpacked even more in later discussions, mainly hinges on the structural set up differences between the WITCH model, that overall entails slower and more costly technological adoption and evolution, and the GCAM model. Looking at the right hand panel of Figure 1 we can immediately notice the difference between WITCH and MARKAL_US: though the magnitude of the variation is roughly the same, the timing is different. Indeed, both models are solved through intertemporal optimization, but in the WITCH model the anticipation effect allows for larger short term adjustments than are allowed for in the MARKAL_US model.

Figure 2 portrays the extent changes in baseline emissions, both in sign and magnitude, are attributable, in a first order approximation, to the individual variations of each input. This type of analysis casts light on the sign of change setting discussed in the methods section. The lines in Figure 2 are the first order effects of the functional ANOVA expansion of $g(x)$ obtained through numerical interpolation. These lines represent the expected variation of output $y$ (in this case cumulative emissions) as a function of each individual model input. The top 
panels in Figure 2 show that the capital cost of nuclear energy is the factor that, when varying in the assigned range, influences the output of both GCAM and WITCH the most. In particular, WITCH reacts almost linearly to changes in the capital cost of nuclear energy, while the reaction in GCAM is non-linear, with a higher rate of change in the low-nuclear energy cost region. As before, the smaller extent of the reaction in WITCH can be explained by the model structure itself which is based on constant elasticity of substitution nested functions to mimic the energy sector (a detailed description of each of the three models is provided in the Appendix). Such a structure is inherently less flexible and implies slower pace of technological shifts than that of models, as for example the GCAM model, that assume other functional relations among technologies, as for example linear aggregation across technologies (see Kriegler et al., 2014 for a comparative analysis and classification of alternative model types). In addition, WITCH includes a constraint on the flexibility of the energy sector technological mix that penalizes excessive penetration of low flexibility technologies (i.e. renewables as well as base load technologies as for example nuclear) versus high flexibility ones (i.e. gas power plants) (Sullivan et al., 2013). A further potential difference between the WITCH and GCAM models is in the way nuclear waste management cost are treated (in WITCH nuclear waste management costs increase with the world cumulated capacity of nuclear capital installed to mimic some sort of saturation effect). However, as the objective of the analysis is to look deeply into model structures and how they might affect models' reactions to input parameter variations, assumptions about nuclear waste management costs were harmonization across the two models. 
Notwithstanding these differences, the direction of change is clear; an increase in nuclear energy costs increases baseline emissions both in WITCH and $\mathrm{GCAM}^{4}$.

In addition, in the GCAM model, bioelectricity efficiency and non-energy costs (and biofuels, to a lesser extent) do play a role in shaping emissions, in particular for high cost (low efficiency) realizations.

\footnotetext{
${ }^{4}$ The slightly oscillatory behavior is mainly due to the smoothing method adopted and the finite sample size.
} 


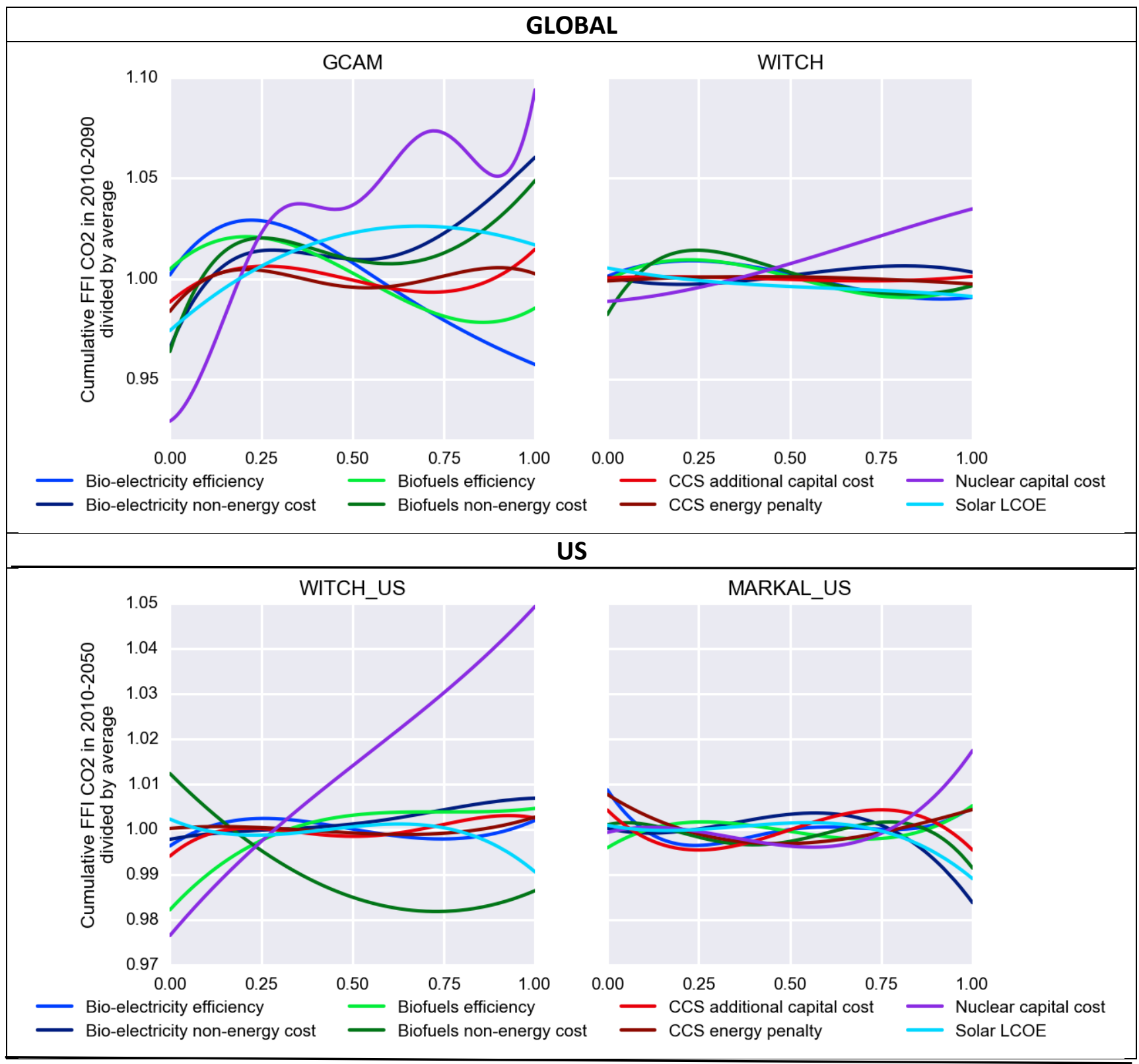

Figure 2: First order effects of the functional ANOVA expansion for the 8 model inputs on global (upper panels) and US (lower panels) cumulative FFI CO2 emissions over the century, according to a functional ANOVA expansion. The realizations of each input are ordered on the $x$-axis from their $\min (=0)$ to their $\max (=1)$.

The lower panel of Figure 2 reports a similar analysis but with a US focus. Within this single region as well, the cost of nuclear energy is again the main player for WITCH. For MARKAL_US, an effect is registered for nuclear energy at the extremes of its variation ranges. However, MARKAL_US, while producing an emission 
variation range comparable to that of the WITCH model for the US (see Figure 1, right hand side panel), displays a very low sensitivity to individual changes in technology costs and efficiency values. The almost horizontal shape of the first order effects and the very overlapped curves practically indicate that the model inputs play the effects of numerical noise, when considered individually. Indeed, the MARKAL_US baseline includes a number of assumptions and policies, in the form of additional constraints, that contribute to a less clear sensitivity to technology costs and efficiency levels when considered as individual determinants of the model output. Conversely, these constraints increase the interaction effects, as confirmed shortly when considering the sensitivity measures in Table 2. Let us describe in detail what these constraints are. First of all, the inclusion of state level renewable portfolio standards (RPS) and wind generation tax credits in MARKAL_US lead to a higher level of renewable generation already by 2020 , and independently on the technological performance realization. Additionally, the assumed ability to apply for a second 20-year life extension for nuclear power plants and the assumption that fossil steam plants do not have fixed retirement schedules (instead the retirements are determined endogenously) also limits the potential market for new technologies. Furthermore, the inclusion of the renewable fuel standard (RFS), as legislated by the Energy Independence and Security act of 2007, requires 36 billion U.S. gallons of biofuels by 2022. Hence, while biomass-based fuels gain market share versus petroleum-based fuels in MARKAL_US, biomass-based power generation is relatively disadvantaged by other fuels in the electric generation market in MARKAL_US. 
Figure 3 reports the ranking of the different parameters for their uncertainty importance. It can immediately be seen that for both GCAM and, to a lesser extent, WITCH nuclear capital costs are, as expected, the key-drivers. The three uncertainty importance indicators tend to agree on their ranking, especially for the first three positions, which are the most relevant for the analysis. 


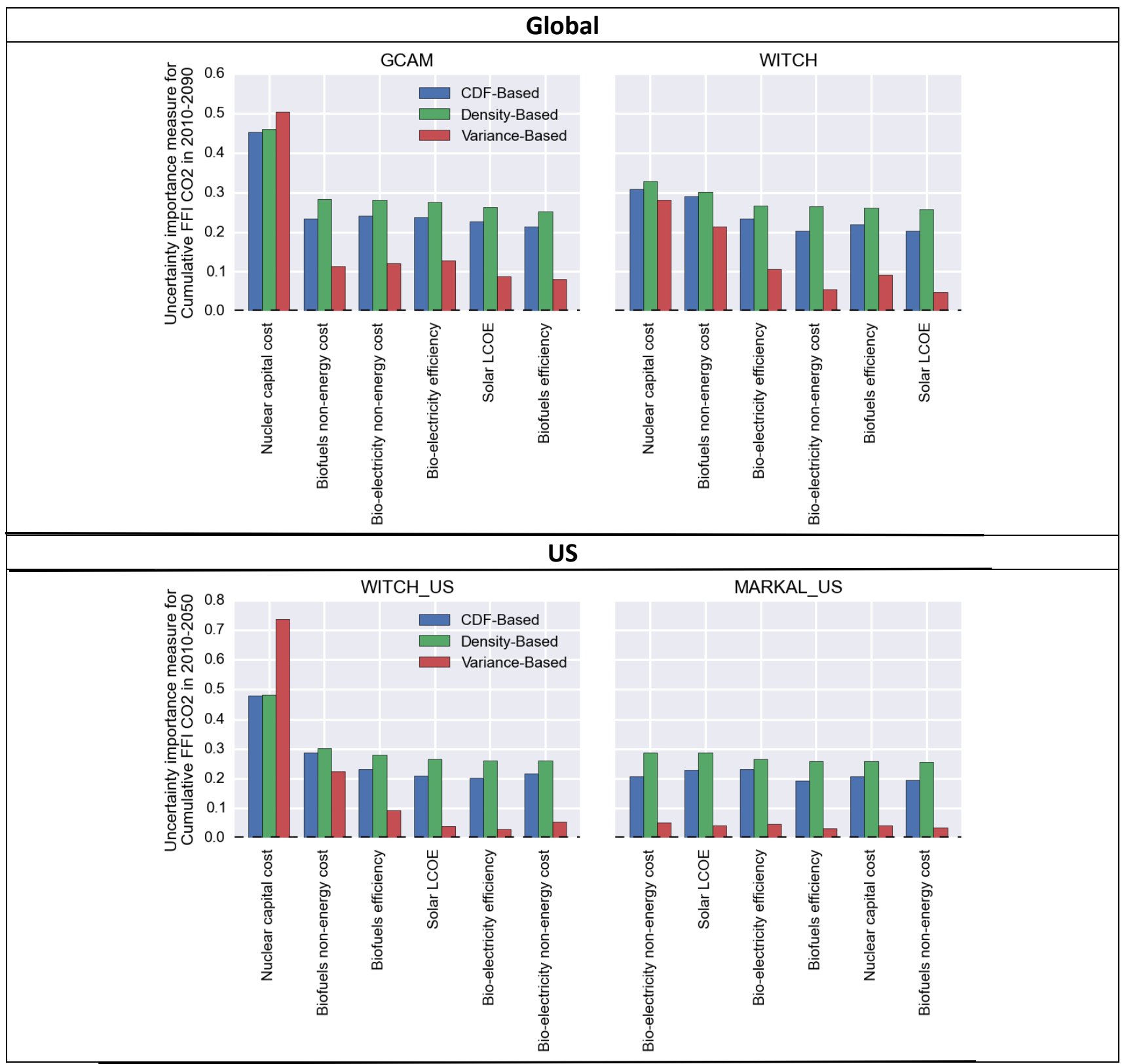

Figure 3: Ranking of uncertainty drivers for global (upper panels) and US (lower panels) cumulative FFI CO2 emissions over the century (over the half century for the US metric). Inputs on the $x$-axis are ordered from most important to least important, according to a density-based measure. In other colors also CDF- and Variance-based indicators are reported.

In the lower inset of Figure 3 a similar set of indicators with a focus on the US is displayed for WITCH and

MARKAL_US. The latter shows an almost uniform sensitivity to the model inputs, as well as an almost null

value for the first order variance-based sensitivity indices. However, distance-based sensitivity measures display 
a non-null value. This combination indicates that individual effects are negligible in MARKAL_US, and that the relevance of model inputs is mainly due to their interactions. As noted before, this is likely to be caused by the inclusion of a number of concurrent policies and constraints in the baseline.

\subsection{Climate Constrained Scenarios}

Let us now move on to the analysis that includes a constraint on global emissions in line with a 4.5 and a 2.6 RCP scenario. The first and most straightforward output to study is the cost of CO2 abatement policy as a share of baseline GDP. Policy costs are measured in slightly different ways in different models (for MARKAL_US only the price of carbon is available and will be discussed below). In WITCH policy costs are measured as the difference in global consumption in the policy case versus the baseline. In GCAM, as GDP is exogenous and independent of the climate policy, the policy cost is measured in the reduction of social surplus, i.e. the area under the marginal abatement cost curve. In both cases costs are discounted at 5\% and reported as share of GDP.

Although these two metrics are not entirely comparable, as a matter of fact they are typically used for relative effort comparisons across models (see for example Clarke, 2009). In particular here, as we are interested in the relative effect of each technology performance rather than on the estimates of climate policy costs per se, it seems appropriate to compare these two metrics. The two models produce fairly comparable cost estimates for the 4.5 RCP scenarios, while they vary widely for the 2.6RCP scenario (see Figure 4). 

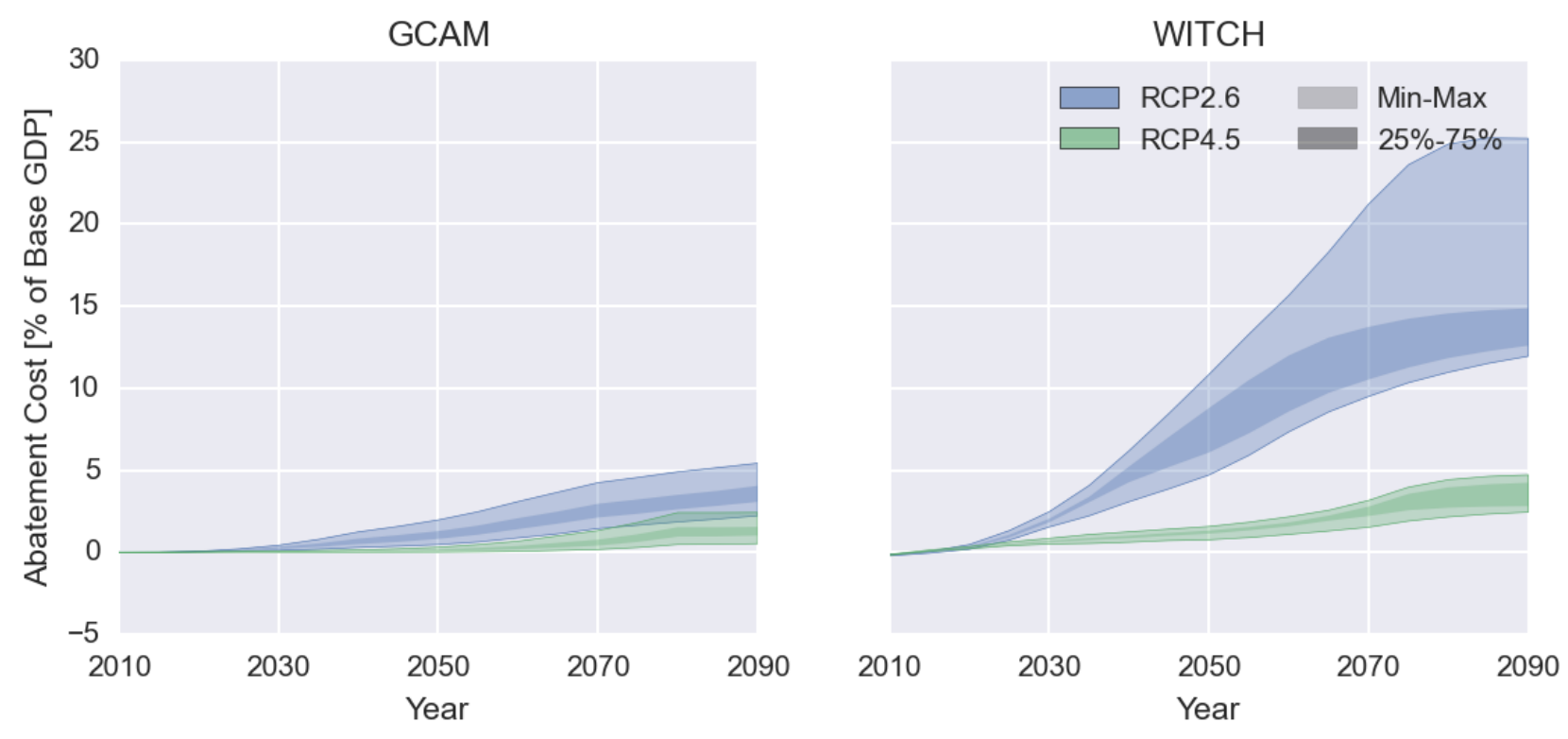

Figure 4: Abatement costs of the two implemented climate policies as percentage of Base GDP. For GCAM, absolute costs are expressed as the area under the MAC curve. In WITCH they correspond to consumption losses.

Notably, WITCH reports much higher costs and a much larger variation in cost realizations associated with the range of technology performance. Figure 5 shows that the models appear to respond monotonically to changes in the technological cost and efficiency space. Visually, we can also appreciate that the first order effect analysis shows a dominance of the nuclear cost realization for GCAM, while biofuels stand out in WITCH. 


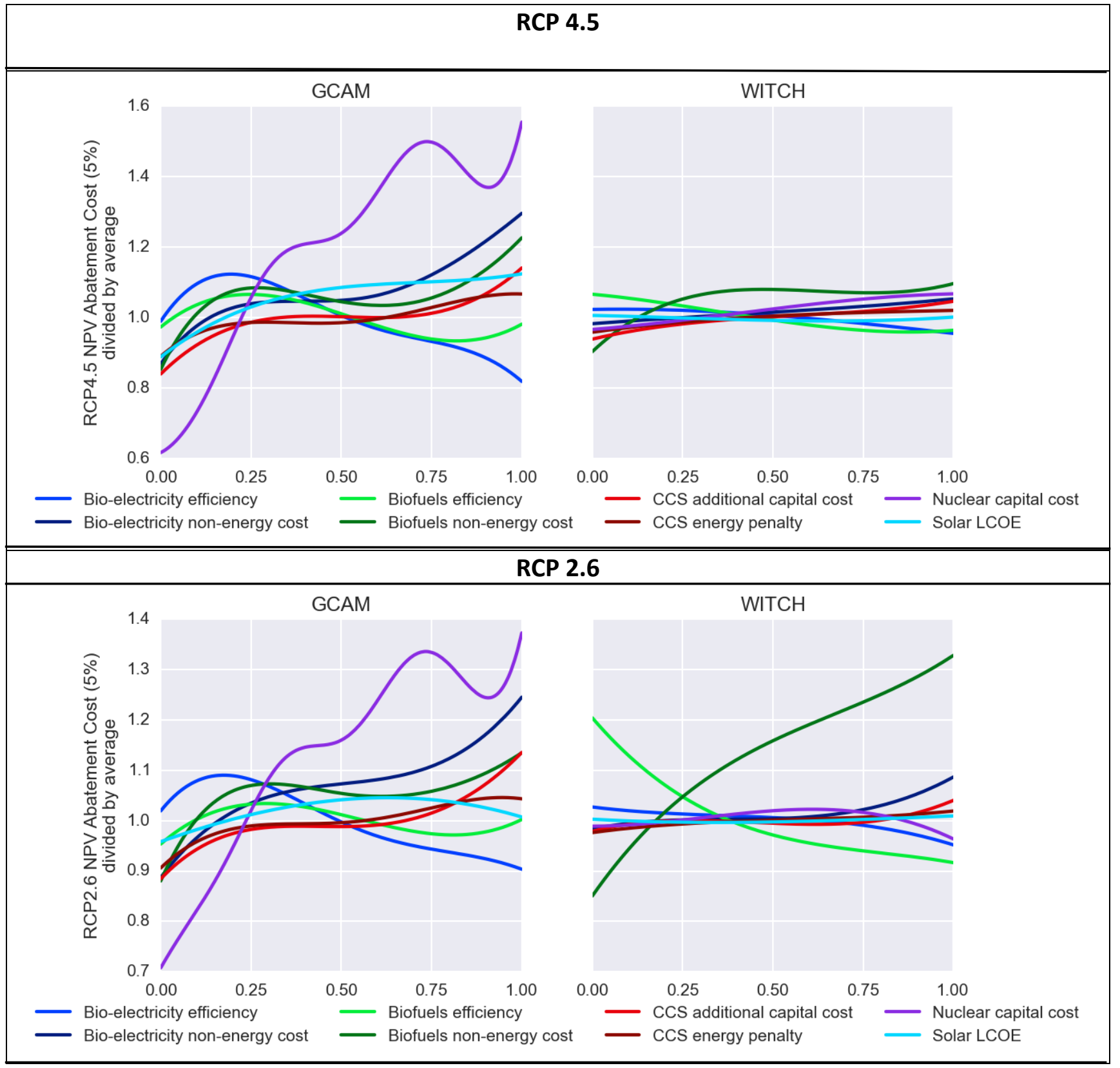

Figure 5: First order effects of the functional ANOVA expansion of discounted abatement costs for the RCP 4.5 (upper two panels) and RCP 2.6 (lower two panels) policies, using a discount rate of $5 \%$.

The dominant technology, though different across the two models, tends to be robust across mitigation targets

(upper and lower insets in Figure 5). This is an important insight that comes from a multi-model comparison. It

suggests that what could be considered as a robust response for a single model becomes less clearcut when 
including several models in the analysis. Obviously, the climate policy cost metric is sensitive to the choice of the discount rate. We also perform the ANOVA analysis for policy cost metrics computed with different discount rates. Although we are not reporting them, results are extremely robust for this additional layer of sensitivity analysis: the first two positions of the ranking do not vary for a wide range of discount rates (as low as $0 \%$, i.e. costs are aggregated undiscounted). This is also true if we consider a different metric altogether, that is if we consider carbon prices. This is shown in Figure 6 for the 2.6 RCP scenario, where we can also include the results for the MARKAL_US model.
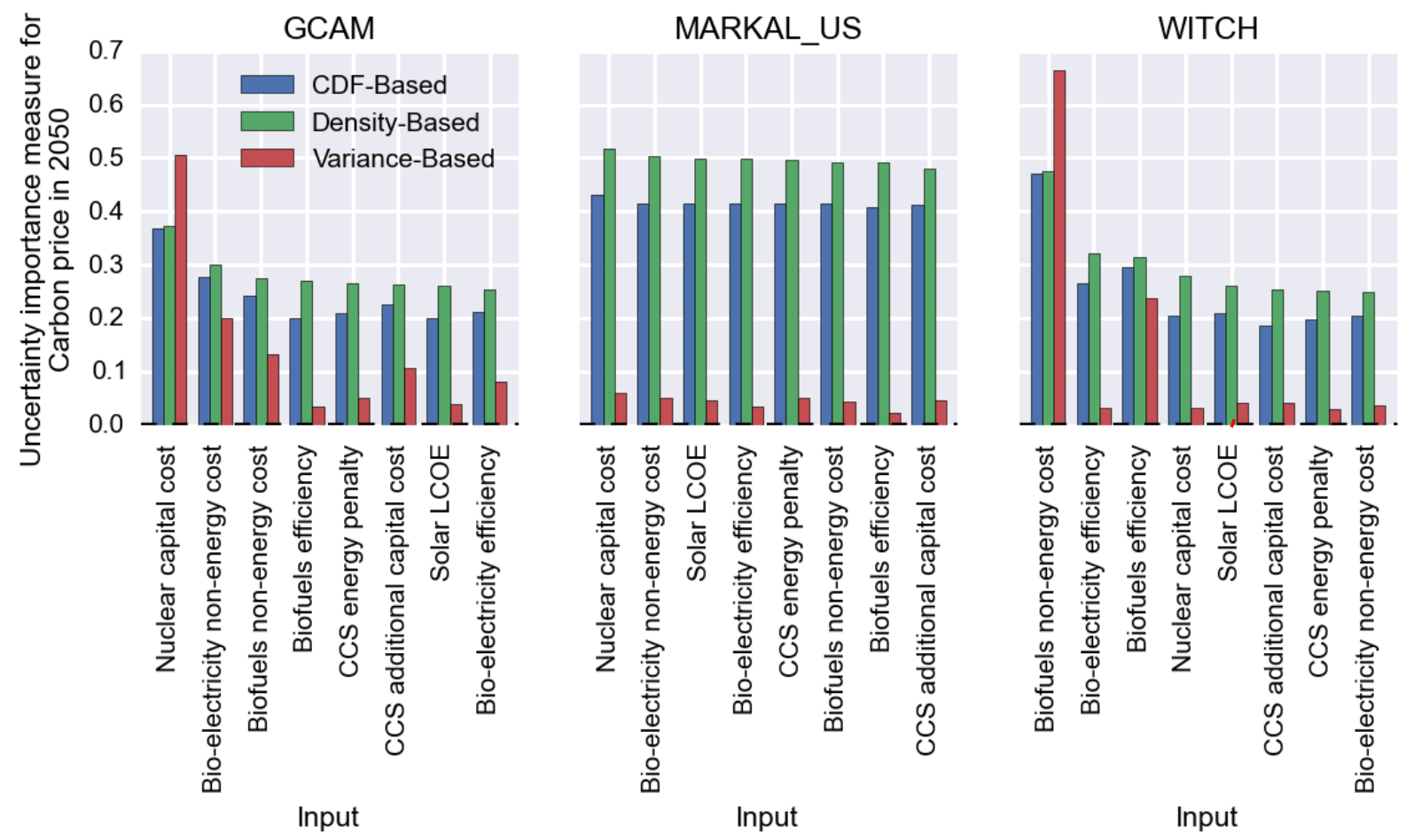

Figure 6: Ranking of uncertainty drivers of Carbon Prices for the RCP 2.6 policy 
To appreciate how the uncertainty in technology costs propagates in the shadow price of carbon before 2050, the full time series of carbon prices for the different models and for both the climate constrained scenarios considered are reported in Figure 7. Despite the structural differences across the models, several similarities can be identified: under the less stringent (RCP4.5) climate scenarios model tend to agree on the median level of the carbon price; uncertainty increases over time; the min-max bands for the two scenarios do not overlap; and the near-term growth rates in the stringent (RCP2.6) scenario are similar.

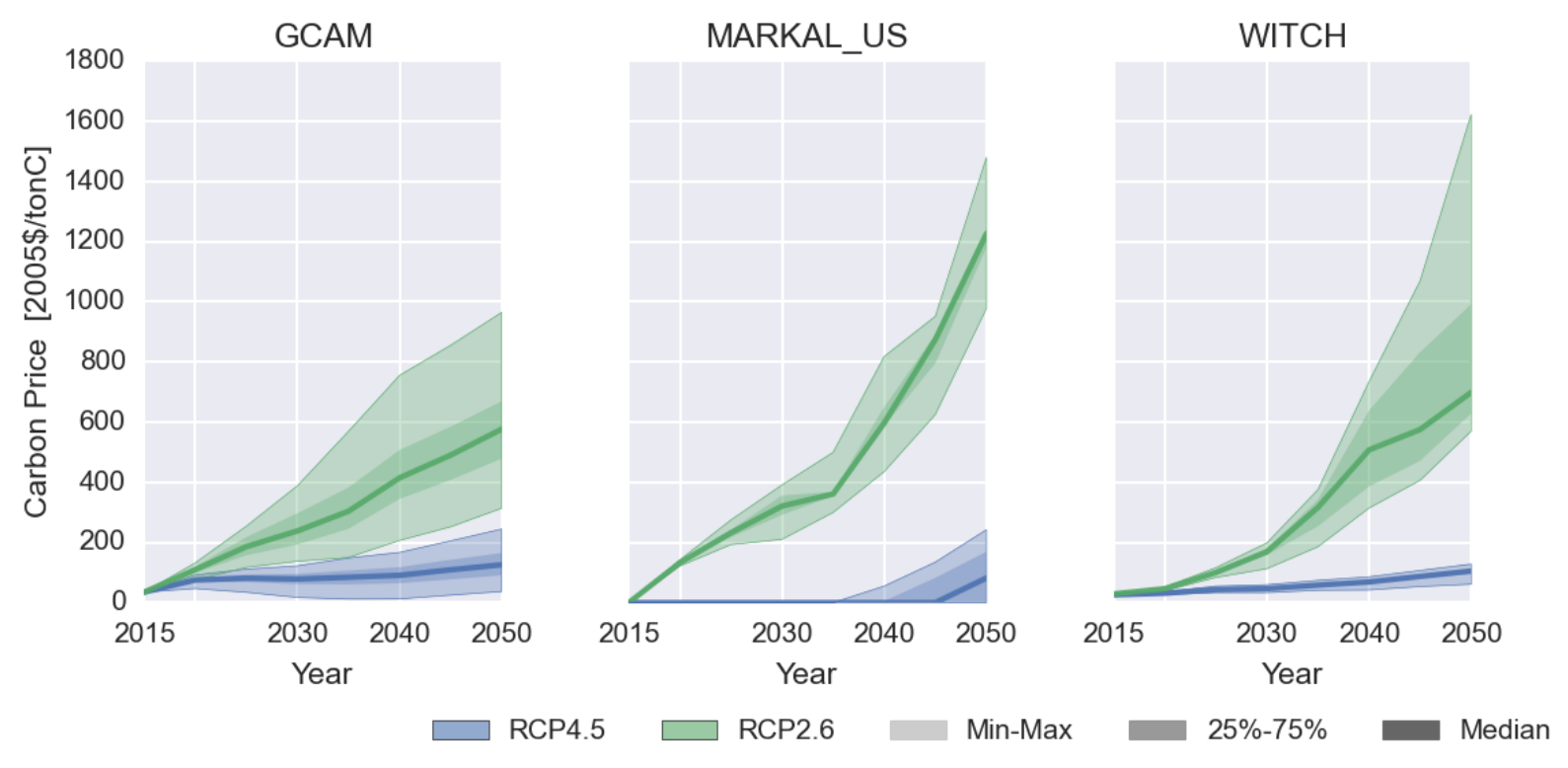

Figure 7: Price of carbon up to 2050 for each of the models in the climate constrained scenarios.

Another common result across models is that both policy costs and carbon prices are more sensitive to technological performance realization, and are so earlier in time, under scenario 2.6 RCP than 4.5 RCP. While in the latter case just a few advanced technologies are sufficient to reach the target, the feasibility and costs of the former scenario rely greatly on the availability of a wider portfolio of cheap and efficient technologies. 
Notwithstanding these similarities, models' structural difference account for the huge variation in the extent and timing of the sensitivity as discussed previously.

Finally, in Figure 8 we show the results of different technology penetrations under the different technology performance realizations. This shows, from a different angle, that GCAM results are more sensitive to technology performance than those of WITCH. At the lowest cost and highest efficiency, GCAM results indicate that renewable and nuclear energies can take up to $60 \%$ and $75 \%$ of the world's electricity supply in 2090 , respectively. In comparison, WITCH results show smaller variance. For instance, at the lowest solar costs considered, the renewables' share of electricity does not exceed $20 \%$, while nuclear energy does not take more than $60 \%$ of the power production mix. These differences bring forward the fundamental structural differences in the model architecture. Given sufficiently low prices, GCAM's flexible structure allows solar, nuclear, or CCS energy to saturate the electricity market. For instance, at $\$ 385 / \mathrm{kW}$ capital cost of nuclear energy, GCAM allows most electricity markets to be dominated by nuclear energy within a few decades. Conversely, at the very unlikely extreme of $\$ 5727 / \mathrm{kW}$ there are virtually no new nuclear plants being built in the future. Such built-in flexibility of the architecture results in a lower cost of abatement, as well as a large sensitivity to either extremes of the technology costs.

On the other hand, WITCH results indicate a more limited role of each technology. For instance, the market penetration of renewables in WITCH is less sensitive to the cost, because of strictly binding constraint on grid- 
integration of intermittent renewables (the constraint on the flexibility of the power generation fleet mentioned early). Similarly, nuclear power generation is constrained in WITCH for a variety of reasons, as the built in flexibility constraint. As we have already mentioned, the greater presence of renewables requires more flexibility in the mix, which is not conveniently provided by nuclear power plants. Hence, instances when both solar and nuclear technologies realization are low cost are not necessarily particularly favorable. 


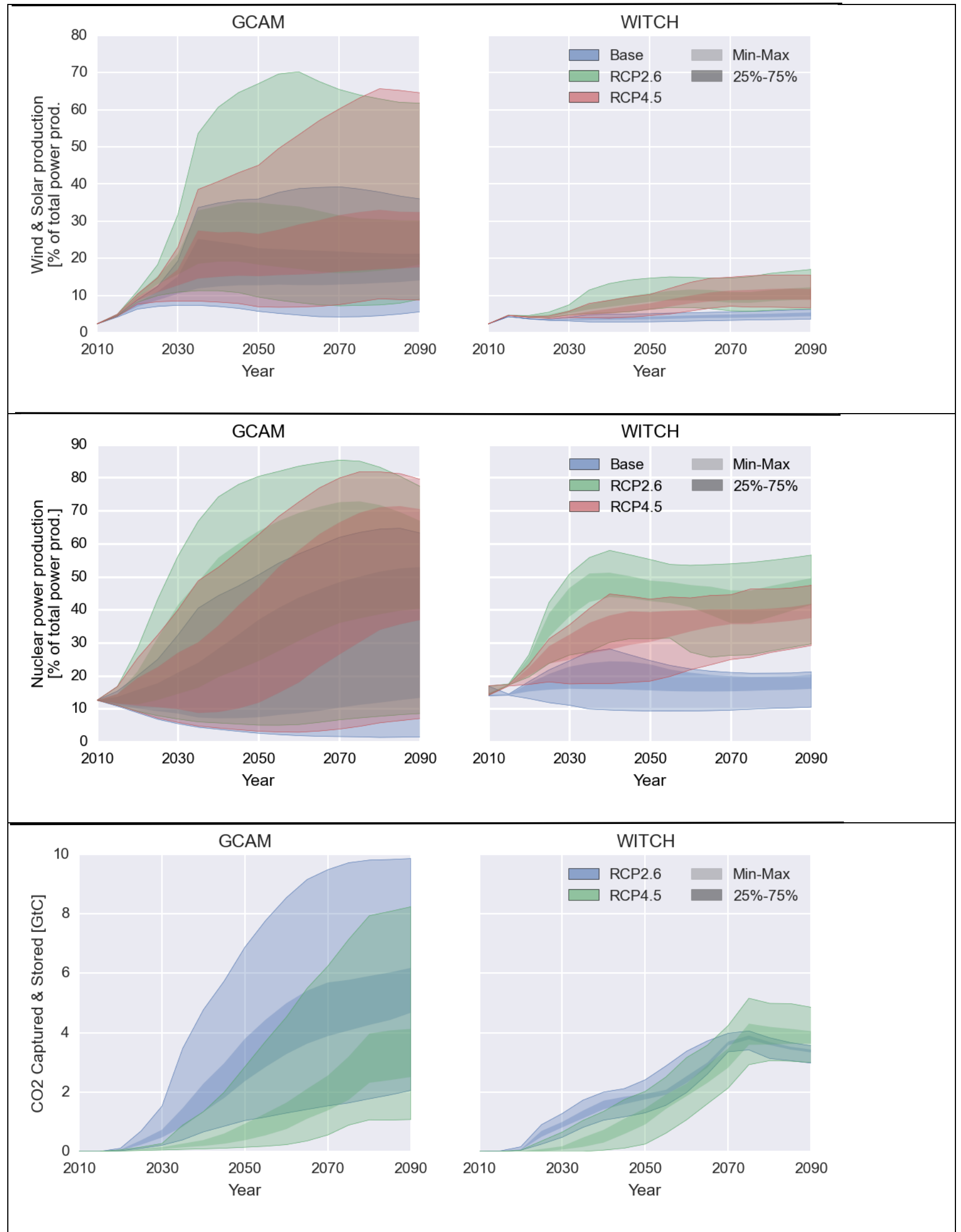

Figure 8: Distributions of three key technology penetrations under the two climate policies and the baseline scenarios considered. Upper panels: Carbon dioxide captured \& stored from fossil fuels and biomass plants with CCS Middle Panels: Wind and solar 
electricity production over total power production. Bottom panels: Nuclear power production as a share of total power production.

CCS technologies are key to the decarbonization implied by the climate policy scenarios under consideration.

Under the RCP 2.6 in particular, with both GCAM and WITCH the minimum level of carbon stored is a considerable 2-3 GtC by the end of the century (notice how this differ from many multi model analysis set up where CCS is considered fully unavailable in the worst case scenario). In WITCH storage of carbon is performed basically independently of its cost and variation is really modest (as said all low carbon technologies are basically required in the mix to comply with these climate targets). In GCAM the deployment of CCS is much more sensitive to the vector of cost realization as more substitution with other technologies is possible.

\section{Conclusions}

This paper investigates the impact that technology assumptions have on a set of alternative environmental and economic metrics across models by means of a well-defined framework taken from the sensitivity analysis literature. This effort is extremely important for improving the usability of models to support policy making. First, because this type of exercise helps unpack the model structure and address the "black box" critique by means of showing the drivers in operation. In addition, given that different metrics might be of interest to policy makers, depending on the focus of the policy under consideration, we explore sensitivity of different types of output of Integrated Assessment models, rather than concentrating on the sole objective function (or policy cost metric). This exercise is also extremely important from the viewpoint of modelers, who can better understand 
what is driving the results of their complex models and, as a consequence, focus their modelling and calibration efforts where it is more crucial in terms of model responses.

In unconstrained emission scenarios, low-carbon technologies have to compete with fossil fuels without accounting for the social cost of emissions. As such, within the range of future technology performances considered in the present analysis, the cost of nuclear energy is shown to dominate all others in affecting future emissions. Although different models imply different variations in baseline emissions, the predominance of nuclear energy cost as the main source of variation across models is a robust result. The variability across models in the magnitude of this effect reflects, in turn, the existence of structural model differences that affect the speed and ease of technology replacements.

Climate-constrained scenarios, and in particular scenarios aiming at a stringent target such as RCP 2.6, stress the relevance, in addition to that of nuclear energy, of biofuels, as they represent the main source of decarbonization of the transportation sector, and bioenergy, since the latter can be coupled with CCS to produce negative emissions. The ranking of the different parameters for their uncertainty importance changes across models, while it is robust for each individual model to changes in the cost metrics and in the stringency of the climate scenario. Some key policy implications may be drawn out of these results. Since climate policy costs are found to be mostly sensitive to the possibility of very cheap or very costly nuclear options, the importance of exploring advanced nuclear possibilities, as well as of better understanding the social acceptability of such technology, 
cannot be neglected by energy R\&D investors and policy makers alike. This will be crucial not only for the climate policy maker who intends to minimize policy costs, but also for the one who wants to reduce the uncertainty surrounding those costs. The same considerations hold for fuels and electricity produced from biomass. In this case, the appetite for research in these technologies, while hindered by potential concerns of economic competition with food production, may be supported by the key role of this technologies in reaching stringent climate targets, related in particular to the possibility of achieving negative emissions.

Looking at available statistics for the United States, a certain attention to nuclear development is already reflected in recent $R \& D$ spending, with around 1 billion USD yearly allocated to nuclear over a total R\&D budget of 5 and 6.5 billions in 2010 and 2011 respectively (IEA RD\&D Database). Moving to biofuels, these figures show a marked drop between 2010 and 2011, decreasing from 0.8 to 0.3 billion USD spent in related R\&D. This may denote a need to strengthen the R\&D efforts in this direction, potentially combined with a synergistic development in technologies like CCS, in order to avoid ruling out technologies that may make a big difference in future. Developing the models to include other technologies, like advanced energy storage solutions, and introducing important synergies, like the one between storage and solar generation, may increase the role of technologies which were assessed to have minor roles in this analysis, like solar.

A further important policy insight that we gain from the MARKAL_US model is that the existence of a complex system of energy policies, which might aim at different objectives and might be designed as independent, but 
which end up interacting and overlapping, might make the energy system reacting in unexpected ways to the potential improvement of the performance of a single technology.

Regarding the methodology, several lessons may be learned from the analysis performed in the present paper, which allow for potential improvements in similar future exercises. In particular, a finer resolution in the sampling would enable a deeper understanding of the mechanisms involved in a models such as MARKAL_US.

Results show that a key role is played by the way and extent models mimic technological adoption and penetration, transition costs and inertia, thus calling for a new set of expert elicitations covering better these topics. Furthermore, the sampling design could account for an analysis of interactions, thus allowing the investigation of potential synergies across pairs of inputs. Nonetheless, the results obtained so far may already inform an initial screening of relevant parameters to be considered in similar sensitivity analyses.

\section{Acknowledgments}

Bosetti acknowledges funding from the European Research Council under the European Community's Seventh Framework Programme (FP7/2007-2013) / ERC grant agreement n॰ 240895 - project ICARUS "Innovation for Climate Change Mitigation: a Study of energy R\&D, its Uncertain Effectiveness and Spillovers". The research work of Bosetti and Marangoni was supported by the Italian Ministry of Education, University and Research and the Italian Ministry of Environment, Land and Sea under the GEMINA project. Anadon acknowledges funding from the Science, Technology, and Public Policy program at the Harvard Kennedy School and grants from the Doris Duke Charitable Foundation and BP to the Energy Technology Innovation Policy research group. McJeon was supported by the Office of Science of the U.S. Department of Energy as part of the Integrated Assessment Research Program. 


\section{References}

Anadon, LD, Bunn, M, Chan, G., Chan, M, Kempener, R, Jones, C, Logar, N., Lee, A, Narayanamurti, V. Transforming U.S. Energy Innovation. (2011). Report. Belfer Center for Science and International Affairs. Harvard Kennedy School, Cambridge, MA.

Anadon, LD, Bosetti, V, Bunn, M, Lee, A. Expert judgments about RD\&D and the future of nuclear energy. Environmental Science \& Technology 41(21) (2012), pp. 11497-11504.

Anadón LD, Chan G, Lee A. Expanding and better targetting U.S. investmnet in energy innovation: an analytical approach. In "Transforming US Energy Innovation", Eds. Anadon, LD, Bunn, M, Narayanamurti, V. Cambridge, U.K., and New York, NY, USA: Cambridge University Press; 2014.

Anderson, B. et al., 2014. Uncertainty in Climate Change Modelling: Can Global Sensitivity Analysis be of Help? Risk Analysis, 34(2), pp.271-293.

Baker, E., Bosetti, V., Diaz Anadon, L., Henrion, M. amd Aleluia da Silva Reis, L. (2014a) Future Costs of Key Green Energy Technologies: Harmonization and Aggregation of Energy Technology Expert Elicitation Data, Submitted to this Energy Policy Special Issue, 2014

Baker, E. Olaleye, O. and Aleluia da Silva Reis, L. (2014b) Decision Frameworks and the investment in R\&D, Submitted to this Energy Policy Special Issue, 2014

Baron, R. \& McJeon, H. (2014) GCAM and Monte Carlo analysis, Submitted to this Energy Policy Special Issue, 2014

Baucells, M. \& Borgonovo, E., 2013. Invariant Probabilistic Sensitivity Analysis. Management Science, 59(11), pp.2536-2549. Available at:

http://www.scopus.com/inward/record.url?eid=2-s2.0-84888863510\&partnerID=tZOtx3y1.

Beccacece, F. \& Borgonovo, E., 2011. Functional \{ANOVA\}, ultramodularity and monotonicity: Applications in multiattribute utility theory. European Journal of Operational Research, 210(2), pp.326-335.

Boden, T. A., Marland, G. \& Andres, R. J. Global, regional, and national fossil-fuel CO2 emissions. Carbon Dioxide Information Analysis Center, Oak Ridge National Laboratory, US Department of Energy, Oak Ridge, Tenn., USA (2009).

Borgonovo, E., 2006. Measuring uncertainty importance: investigation and comparison of alternative approaches. Risk analysis?: an official publication of the Society for Risk Analysis, 26(5), pp.1349-1361.

Borgonovo, E., 2007. A new uncertainty importance measure. Reliability Engineering and System Safety, 92(6), pp.771-784.

Chan, G, Anadon, LD, Chan, M, Lee, A. Expert Elicitation of Cost, Performance, and RD\&D Budgets for Coal Power with CCS. Energy Procedia 4 (2011), pp. 2685-2692.

Clarke, L., J. Edmonds, V. Krey, R. Richels, S. Rose, and M. Tavoni. "International Climate Policy Architectures: Overview of the EMF 22 International Scenarios." Energy Economics 31 (2009): S64-S81.

Edmonds, J. \& Reilly, J. Global energy and CO2 to the year 2050. The Energy Journal 4, 21-48 (1983).

Edmonds, J. \& Reilly, J. Global energy production and use to the year 2050. Energy 8, 419-432 (1983).

Edmonds, J.A., Calvin, K.V., Clarke, L.E., Janetos, A.C., Kim, S.H., Wise, M.A., and McJeon, H.C., 2012. Integrated Assessment Modeling, in Encyclopedia of Sustainability Science and Technology, Vol. 1, ed. R.A. Meyers. Springer Reference, New York, NY.

ETSAP. Energy Technology Systems Analysis Program, (2010) [cited 2009 May 29]; Available from: http://www.etsap.org/index.asp. 
Fishbone, L. G. and H. Abilock (1981). Markal, a linear-programming model for energy systems analysis: Technical description of the BNL version. International Journal of Energy Research 5(4): 353-375.

Glick, N., 1975. Measurements of separation among probability densities or random variables. Canadian Journal of Statistics, 3(2), pp.267-276.

Glynn, Peter W., and Donald L. Iglehart. "Importance Sampling for Stochastic Simulations." Management Science 35, no. 11 (1989): 1367-92.

Hamilton LD, Goldstein G, Lee JC, Manne A, Marcuse W, Morris SC, and Wene C-O. (1992) MARKALMACRO: An Overview. Brookhaven National Laboratories, November 1992

Helton, J.C., 1993. Uncertainty and sensitivity analysis techniques for use in performance assessment for radioactive waste disposal. Reliability Engineering and System Safety, 42(2-3), pp.327-367.

IIASA. (2010). RCP Database (version 2.0.5). Retrieved from International Institute for Applied Systems Analysis: http://tntcat.iiasa.ac.at:8787/RcpDb

International Energy Agency. Energy balances of OECD countries (2007)

International Institute for Applied Systems Analysis 2013, SSP Database. Available: https://secure.iiasa.ac.at/web-apps/ene/SspDb/dsd?Action=htmlpage\&page=about [2014, May 28].

IPCC, W. (2014). Climate Change 2014: Mitigation of Climate Change. Cambridge, UK.: Contribution of Working Group III to the Fifth Assessment Report of the Intergovernmental Panel on Climate Change, Cambridge University Press.Lemoine, D.M. and McJeon, H.C., 2013. Trapped between two tails: trading off scientific uncertainties via climate targets. Environ. Res. Lett. 8: 034019.

Kriegler, E., Petermann, N., Krey, V., Schwanitz, V. J., Luderer, G., Ashina, S., Bosetti, V., Eom, J., Kitous, A., Méjean, A., Paroussos, L., Sano, F., Turton, H., Wilson, C., Van Vuuren, D. P. (2014). Diagnostic indicators for integrated assessment models of climate policy. Technological Forecasting and Social Change.

Kriegler, E. Weyant, J.P., Blanford, G.J., Krey, V. Clarke, L., Edmonds, J., Fawcett, A., et al. "The Role of Technology for Achieving Climate Policy Objectives: Overview of the EMF 27 Study on Global Technology and Climate Policy Strategies." Climatic Change 123, no. 3-4 (April 2014): 353-67. doi:10.1007/s10584-0130953-7.

Lewandowski, D., Cooke, R.M. \& Duintjer Tebbens, R.J., 2007. Sample-Based Estimation of Correlation Ratio with Polynomial Approximation. ACM Transactions on Modeling and Computer Simulation, 18(1), pp.3:1-3:16.

Loulou R., Goldstein G. \& Noble K. (2004). Documentation for the MARKAL Family of Models. Energy Technology Systems Analysis Program (ETSAP); Available from: http://www.iea-etsap.org/web/MrklDocI_StdMARKAL.pdf

McJeon, H. C., Clarke, L., Kyle, P., Wise, M., Hackbarth, A., Bryant, B.P. and Lempert, R.J. "Technology Interactions among Low-Carbon Energy Technologies: What Can We Learn from a Large Number of Scenarios?" Energy Economics 33, no. 4 (2011): 619-31.

Morgan, M.G., 2014. Use (and abuse) of expert elicitation in support of decision making for public policy. Proc. Natl. Acad. Sci. 111, 7176-7184. doi:10.1073/pnas.1319946111.

Pearson, K., 1905. On the General Theory of Skew Correlation and Non-linear Regression, London: Dulau \& Co.

Plischke, E., 2012. How to compute variance-based sensitivity indicators with your spreadsheet software. Environmental Modelling \& Software, 35, pp.188-191.

Plischke, E., Borgonovo, E. \& Smith, C.L., 2013. Global sensitivity measures from given data. European Journal of Operational Research, 226(3), pp.536-550. 
Rabitz, H. \& Aliş, Ö.F., 1999. General foundations of high-dimensional model representations. Journal of Mathematical Chemistry, 25(2-3), pp.197-233.

Ratto, M., Pagano, A. \& Young, P., 2007. $\{$ S $\}$ tate $\{\mathrm{D}\}$ ependent $\{\mathrm{P}\}$ arameter metamodelling and sensitivity analysis., 177, pp.863-876.

Riahi, K., Kriegler, E., Johnson, N., Bertram, C., den Elzen, M. Eom, J., Schaeffer, M. et al. "Locked into Copenhagen Pledges - Implications of Short-Term Emission Targets for the Cost and Feasibility of Long-Term Climate Goals." Technological Forecasting and Social Change, November 2013. doi:10.1016/j.techfore.2013.09.016.

Rogelj, J., McCollum, D.L., O'Neill, B.C. and Riahi, K.. "2020 Emissions Levels Required to Limit Warming to below $2{ }^{\circ}$ C." Nature Climate Change 3, no. 4 (December 16, 2012): 405-12. doi:10.1038/nclimate1758.

Saltelli, A. et al., 2008. Global Sensitivity Analysis -- The Primer, Chichester.

Saltelli, A. et al., 2005. Sensitivity Analysis for Chemical Models. Chemical Reviews, 105, pp.2811-2828.

Saltelli, A., 2002. Sensitivity Analysis for Importance Assessment. Risk Analysis, 22(3), pp.579-590.

Samuelson, P., 1947. Foundations of Economic Analysis, Harvard University Press, Cambridge, MA.

Sullivan, P., Krey, V., and Riahi, K. (2013). Impacts of considering electric sector variability and reliability in the MESSAGE model. Energy Strategy Reviews, 1, 157-163.

Tygert, M., 2010. Statistical Tests for whether a given set of independent, identically distributed draws comes from a specified probability density. PNAS, 107(38), pp.16471-16476.

Wigley, T. \& Raper, S. Reasons for Larger Warming Projections in the IPCC Third Assessment Report. Journal of Climate 15 (2002).

Wise, M. et al. Implications of limiting CO2 concentrations for land use and energy. Science 324, 1183-1186 (2009).

Ziehn, T. \& Tomlin, A.S., 2009. \{GUI-HDMR\} - A software tool for global sensitivity analysis of complex models., 24, pp.775-785. 


\section{Appendix: IA Models Description}

\section{GCAM 2.1 Model}

Table A1: Summary of GCAM features.

\begin{tabular}{|c|c|}
\hline $\begin{array}{l}\text { Model Concept } \\
\text { Integrated assessment model of Energy-Land- } \\
\text { Climate. Detailed market equilibrium model for } \\
\text { energy and agricultural goods. Embedded simple } \\
\text { climate model. }\end{array}$ & $\begin{array}{l}\text { Solution Method } \\
\text { The model is solved for a set of market clearing } \\
\text { prices for each period using a combination of } \\
\text { Bisection and Newton-Raphson methods. }\end{array}$ \\
\hline $\begin{array}{l}\text { Welfare Concept } \\
\text { Net present value of consumer and producer } \\
\text { surplus. }\end{array}$ & $\begin{array}{l}\text { Parametric Specification } \\
\text { Discount rate }=5 \%\end{array}$ \\
\hline $\begin{array}{l}\text { Markets and Trade } \\
\text { Emission permits, primary energy, and agricultural } \\
\text { products traded on a single worldwide market. } \\
\text { Regional markets for secondary energy. }\end{array}$ & $\begin{array}{l}\text { Model anticipation } \\
\text { Static Foresight }\end{array}$ \\
\hline \multicolumn{2}{|c|}{$\begin{array}{l}\text { Model Regions: } 14 \\
\text { Africa } \\
\text { Australia and New Zealand } \\
\text { Canada } \\
\text { China } \\
\text { Eastern Europe } \\
\text { Former Soviet Union } \\
\text { India } \\
\text { Japan } \\
\text { Korea } \\
\text { Latin America } \\
\text { Middle East } \\
\text { Southeast Asia } \\
\text { USA } \\
\text { Western Europe }\end{array}$} \\
\hline $\begin{array}{l}\text { Base year } \\
2005\end{array}$ & $\begin{array}{l}\text { Time horizon and step } \\
\text { 2005-2095, } 5 \text { years }\end{array}$ \\
\hline $\begin{array}{l}\text { Climate } \\
\text { Greenhouse gases: } \\
\mathrm{CO} 2, \quad \mathrm{CH} 4, \quad \mathrm{~N} 2 \mathrm{O}, \mathrm{HFCs}, \mathrm{PFCs}, \mathrm{SF} 6, \mathrm{CO}, \\
\text { NOx, VOC, SO2, BC, OC. } \\
\text { Aerosols Considered: yes }\end{array}$ & $\begin{array}{l}\text { Climate Change } \\
\text { Model for the Assessment of Greenhouse Gas } \\
\text { Induced Climate Change (MAGICC 5.3) } \\
\text { CO2 concentration }(\mathrm{ppm}) \\
\text { Radiative forcing }(\mathrm{W} / \mathrm{m} 2) \\
\text { Temperature change }\left({ }^{\circ} \mathbf{C}\right)\end{array}$ \\
\hline $\begin{array}{l}\text { Mitigation options } \\
\text { Abatement cost functions for non-CO2 GHGs } \\
\text { Land use } \\
\text { Decarbonization options in the energy system } \\
\text { (renewables, nuclear, biomass, ccs) }\end{array}$ & $\begin{array}{l}\text { Climate Impacts } \\
\text { Not modeled }\end{array}$ \\
\hline $\begin{array}{l}\text { Land use } \\
\text { Emissions from land use change are considered }\end{array}$ & $\begin{array}{l}\text { Resources considered } \\
\text { Coal, Oil, Gas, Uranium, Biomass, Carbon Storage }\end{array}$ \\
\hline
\end{tabular}




\section{Overview}

The Global Change Assessment Model (GCAM) is a global integrated assessment model of energy, economy, land-use, and climate. GCAM is originated from the Edmonds and Reilly model (Edmonds \& Reilly 1983, Edmonds \& Reilly, 1983).

In this paper, we use the standard release of GCAM 2.1 with elicited technologies specifically modified to reflect the common assumptions on the future technology performances. GCAM is an open-source model $^{5}$ primarily developed and maintained at the Joint Global Change Research Institute. The full documentation of the model is available at GCAM wiki page (available at http://wiki.umd.edu/gcam/).), and the following description is a summary of the wiki documentation.

GCAM is a long-term global model with particular emphasis on the representation of human dimensions of the Earth system. GCAM integrates representations of the global economy, energy systems, agriculture and land use, with representation of terrestrial and ocean carbon cycles, a suite of coupled gas-cycle and climate models.

The climate and physical atmosphere in GCAM is represented by the Model for the Assessment of Greenhouse-Gas Induced Climate Change (MAGICC) version 5.3 (Wigley and Raper, 2002). The emission trajectories of greenhouse gases are modeled in GCAM's energy and land-use components.

The global economy of GCAM is represented in 14 geopolitical regions, explicitly linked through international trade in energy commodities, agricultural and forest products, and other goods such as emissions permits. The scale of economic activity is driven by population size, age and gender, and labor productivity that determine economic output in each region. The energy and land-use market equilibrium is established in each period by solving for a set of market-clearing prices for all energy and agricultural good markets. This equilibrium is dynamic-recursively solved for every 5 years over 2005-2100. Table A1 above provides an overview of the other key features of GCAM.

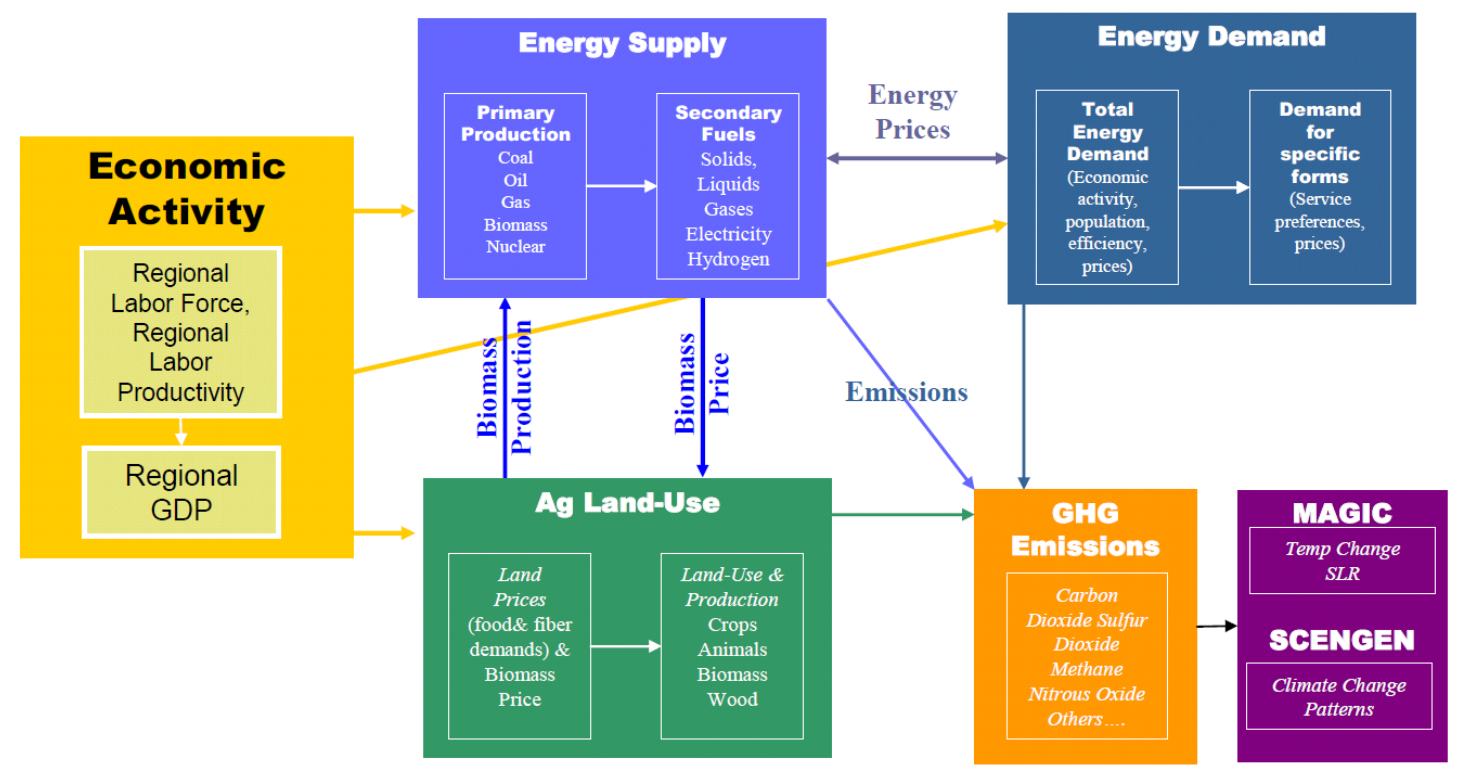

Fig. A1 Overview of the GCAM model.

GCAM combines representations of the global economy, energy systems, agriculture and land use, with representation of terrestrial and ocean carbon cycles, a suite of coupled gas-cycle and climate models.

Source: Wise et al. 2009.

\section{Modeling energy system}

In GCAM, the energy system represents processes of energy resource extraction, transformation, and delivery, ultimately producing services demanded by end users. Resources are classified as either depletable or renewable; in either case, the extraction costs of a given resource are assumed to increase as economically

\footnotetext{
${ }^{5}$ GCAM Source Code and Data (available at http://www.globalchange.umd.edu/models/gcam/).
} 
attractive resources are employed, but are also subject to technological progress which can lower extraction costs for a given resource grade. In each time period, the market prices of energy goods and services, including fossil fuel resources, are determined within the market equilibrium.

Fossil fuel energy is produced from a graded, regionally disaggregated depletable resource base. Renewable energy forms are also disaggregated by region, and resource grade; however, by their nature the resource is not consumed by use. Primary energy forms can be transformed into final energy products, including electricity, processed gas products, refined liquids, and so on.

Energy transformation sectors convert resources initially into fuels consumed by other energy transformation sectors, and ultimately into goods and services consumed by end users. Multiple technologies compete for market share; shares are allocated among competing technologies using a logit choice formulation (Clarke \& Edmonds, 1993). The cost of a technology in any period depends on two key exogenous input parameters - the non-energy cost and the efficiency of energy transformation-as well as the prices of the fuels it consumes. The non-energy cost represents all fixed and variable costs incurred over the lifetime of the equipment (except for fuel costs), expressed per unit of output. For example, a gas-fired electricity plant incurs a range of costs associated with construction (a capital cost) and annual operations and maintenance. The efficiency of a technology determines the amount of fuel required to produce each unit of output. The prices of fuels are calculated endogenously in each time period based on supplies, demands, and resource depletion. The depletion of economically available energy resources are explicitly tracked throughout the modeling period.

\section{Modeling CO2 emissions}

GCAM tracks 16 different greenhouse gases, aerosols and short-lived species. Fossil fuel $\mathrm{CO}_{2}$ emissions are modeled according to the following method:

1. The total emission in the base year is calibrated to the Carbon Dioxide Information Analysis Center (CDIAC) database (Boden et al, 2009) The fossil fuel consumption in the base year is calibrated to the International Energy Agency (IEA) Energy Balances Database 2007.

2. The average emission coefficients are derived from the ratio of the total emission and the total fuel consumption for each fuel (Coal, Oil, and Gas).

3. These emission coefficients are applied to each sector in the base year.

4. For future periods, GCAM solves for market shares of each fuel in each sector, and the emissions are calculated by the product of emission coefficients and the fuel consumption in each sector.

\section{Modeling key TEAM Technologies}

Capital costs, fuel costs, and other non-energy costs are amortized to yield the levelized cost of electricity (LCOE) for each technology. Multiple technologies compete for market share; shares are allocated among competing technologies using a logit choice formulation (Clarke \& Edmonds, 1993).

Renewables integration is limited to $30 \%$ of grid capacity, at which point each additional unit of renewable power requires either an equivalent unit of gas0fired backup or battery backup. Fuel costs are determined endogenously by the model. The cost of biomass is endogenously determined by the land-use module. CCS is available for all fuel types starting in the year 2020. The additional capital cost and the additional fuel requirement is amortized and added to the standard powerplants powered by fossil fuel or biomass. CO2 storage can also be treated as a finite geographically distributed resource in GCAM. In this mode GCAM distinguishes five candidate geologic storage reservoirs types: (i) On-shore deep saline formations; (ii) Off-shore deep saline formations; (iii) Depleted oil fields; (iv) Depleted gas fields; (v) Unminable coal deposits. Each type of reservoir is associated with a cost of storage ranging from $\$ 0.036 / \mathrm{tCO} 2$ to $\$ 100 / \mathrm{tCO} 2$, depending on the difficulty of access (http://wiki.umd.edu/gcam). 
All non-energy inputs evolve according to the learning equation presented in the paper, where the 2005 value is chosen in consistency with the previous 2005 calibration of the model and are summarized in the table below. Nuclear capital cost and CCS additional capital cost are amortized assuming 15\% FCR and 90\% capacity factor. Solar LCOE, and bioelectricity and biofuel additional capital cost do not require any conversion as they're already elicited in levelized costs. Efficiencies are converted from HHV to LHV. See (Baron et al. 2014) for a detailed discussion of the conversion process. A fixed fee of $1 \mathrm{mill} / \mathrm{kWhr}(0.1 \mathrm{cent} / \mathrm{kWhr})$ is charged to nuclear electricity generated for the development and eventual disposal of spent fuel in Yucca Mountain. We apply a fixed cost for waste disposal based on the US disposal fee and utilize a range of assumptions for the potential availability of repository capacity. Uranium supply curve is an upwards sloping curve documented in (http://wiki.umd.edu/gcam). At moderate levels of nuclear deployment, they cost of uranium is around $\$ 100 / \mathrm{kg}$ (about 0.3 cents $/ \mathrm{kWh}$ ), but as more nuclear power is deployed, it could drive up the cost of uranium to $\$ 250 / \mathrm{kG}$ or more.

Table A2: Summary of TEAM Technologies characteristics in GCAM

\begin{tabular}{lll}
\hline Technology & $\mathbf{2 0 0 5}$ value & Unit \\
\hline Bio-electricity efficiency & 38.29 & $\% \mathrm{HHV}$ \\
Bio-electricity non-energy cost & 0.0511 & $2010 \$ / \mathrm{KWh}$ \\
Biofuels efficiency & 44.76 & $\% \mathrm{HHV}$ \\
Biofuels non-energy cost & 0.91 & $2010 \$ / \mathrm{GGE}$ \\
CCS additional capital cost & 3353.05 & $2010 \$ / \mathrm{KW}$ \\
CCS energy penalty & 42.8 & $\%$ \\
Nuclear capital cost & 2859.89 & $2010 \$ / \mathrm{kW}$ \\
Solar LCOE & 0.592 & $2010 \$ / \mathrm{KWh}$ \\
\hline
\end{tabular}

\section{WITCH Model}

Table A3: Summary of WITCH features.

\begin{tabular}{|c|c|}
\hline Name and Version: WITCH 2014 & $\begin{array}{l}\text { Model developer and main users: } \\
\text { Fondazione Eni Enrico Mattei }\end{array}$ \\
\hline $\begin{array}{l}\text { Model objective: } \\
\text { WITCH evaluates the impacts of climate policies on global and } \\
\text { regional economic systems and provides information on the optimal } \\
\text { responses of these economies to climate change. The model } \\
\text { considers the positive externalities from leaning-by-doing and } \\
\text { learning-by-researching in the technological change. }\end{array}$ & $\begin{array}{l}\text { Model concept: Hybrid } \\
\text { Economic optimal growth model, } \\
\text { including a bottom-up energy sector and } \\
\text { a simple climate model, embedded in a } \\
\text { game theoretic setup. }\end{array}$ \\
\hline $\begin{array}{l}\text { Solution Method: } \\
\text { Regional growth models solved by non-linear optimization and } \\
\text { game theoretic setup solved by tatonnement algorithm (cooperative } \\
\text { solution: Negishi welfare aggregation, non-cooperative solution: } \\
\text { Nash equilibrium) }\end{array}$ & Base year: 2005 \\
\hline Time Horizon, and time steps: $2005-2150,5$-year period. & Model anticipation: Perfect Foresight \\
\hline $\begin{array}{l}\text { Coverage and regions: } \\
\text { Global. } 14 \text { regions. } \\
\text { cajaz: Canada, Japan, New Zeland } \\
\text { china: China, including Taiwan } \\
\text { easia: South East Asia } \\
\text { india: India } \\
\text { kosau: South Korea, South Africa, Australia }\end{array}$ & $\begin{array}{l}\text { Policy implementation: } \\
\text { Quantitative climate targets (temperature, } \\
\text { radiative forcing, concentration), carbon } \\
\text { budgets, emissions profiles as } \\
\text { optimization constraints. } \\
\text { Carbon taxes. } \\
\text { Allocation and trading of emission }\end{array}$ \\
\hline
\end{tabular}




\begin{tabular}{|c|c|}
\hline $\begin{array}{l}\text { laca: Latin America, Mexico and Caribbean } \\
\text { indo: Indonesia } \\
\text { mena: Middle East and North Africa } \\
\text { neweuro: EU new countries + Switzerland + Norway } \\
\text { oldeuro: EU old countries (EU-15) } \\
\text { sasia: South Asia } \\
\text { ssa: Sub Saharan Africa } \\
\text { te: Non-EU Eastern European countries, including Russia } \\
\text { usa: United States of America }\end{array}$ & $\begin{array}{l}\text { permits, banking and borrowing. } \\
\text { Subsidies, taxes and penalty on energies } \\
\text { sources. }\end{array}$ \\
\hline $\begin{array}{l}\text { Economic sectors (represented separately in terms of value } \\
\text { added): } \\
\square \text { Agriculture } \\
\square \text { Industry } \\
\text { X Energy } \\
\square \text { Transport } \\
\square \text { Services } \\
\text { X Other }\end{array}$ & $\begin{array}{l}\text { Exogenous Model Drivers: } \\
\square \text { Exogenous GDP } \\
\text { X Total Factor Productivity } \\
\text { X Labour Productivity } \\
\text { X Capital Technical progress } \\
\square \text { Energy Technical progress } \\
\square \text { Materials Technical progress } \\
\square \text { GDP per capita } \\
\square \text { Other }\end{array}$ \\
\hline $\begin{array}{l}\text { If other, please list or give number. If no separate sectors please } \\
\text { give brief explanation of economy: } \\
\text { A single economy sector is represented. Production inputs are } \\
\text { capital, labor and energy services, accounting for the Energy sector } \\
\text { split into } 8 \text { energy technologies sectors (coal, oil, gas, wind\&solar, } \\
\text { nuclear, electricity and biofuels). }\end{array}$ & $\begin{array}{l}\text { If other types or endogenous drivers, } \\
\text { please describe: } \\
\text { In the energy sector: endogenous } \\
\text { Learning-By-Doing and endogenous } \\
\text { Learning-By-Researching. }\end{array}$ \\
\hline $\begin{array}{l}\text { Development: } \\
\text { X GDP per capita } \\
\square \text { Income distribution in a region } \\
\square \text { Urbanisation rate } \\
\square \text { Education level } \\
\square \text { Labour participation rate } \\
\square \text { Other } \\
\text { If other, please briefly describe: }\end{array}$ & $\begin{array}{l}\text { Behaviour and behavioural change: } \\
\text { Production function with constant } \\
\text { elasticity of substitution. }\end{array}$ \\
\hline $\begin{array}{l}\text { Cost measures: } \\
\text { X GDP loss } \\
\text { X Welfare loss } \\
\text { X Consumption loss } \\
\square \text { Area under MAC } \\
\text { X Energy system costs } \\
\square \text { Other } \\
\text { If other, please briefly describe: }\end{array}$ & $\begin{array}{l}\text { Trade: } \\
\text { X Coal X Oil } \\
\text { X Gas } \square \text { Uranium } \\
\square \text { Electricity } \\
\square \text { Bioenergy crops } \square \text { Food crops } \\
\square \text { Capital } \\
\text { X Emissions permits } \\
\square \text { Non-energy goods } \\
\square \text { Other } \\
\text { If other, please briefly describe: }\end{array}$ \\
\hline $\begin{array}{l}\text { Resource Use: } \\
\text { X Coal } \\
\text { X Oil } \\
\text { X Gas }\end{array}$ & $\begin{array}{l}\text { Electricity technologies: } \\
\text { X Coal X Gas } \\
\text { X Oil X Nuclear }\end{array}$ \\
\hline
\end{tabular}




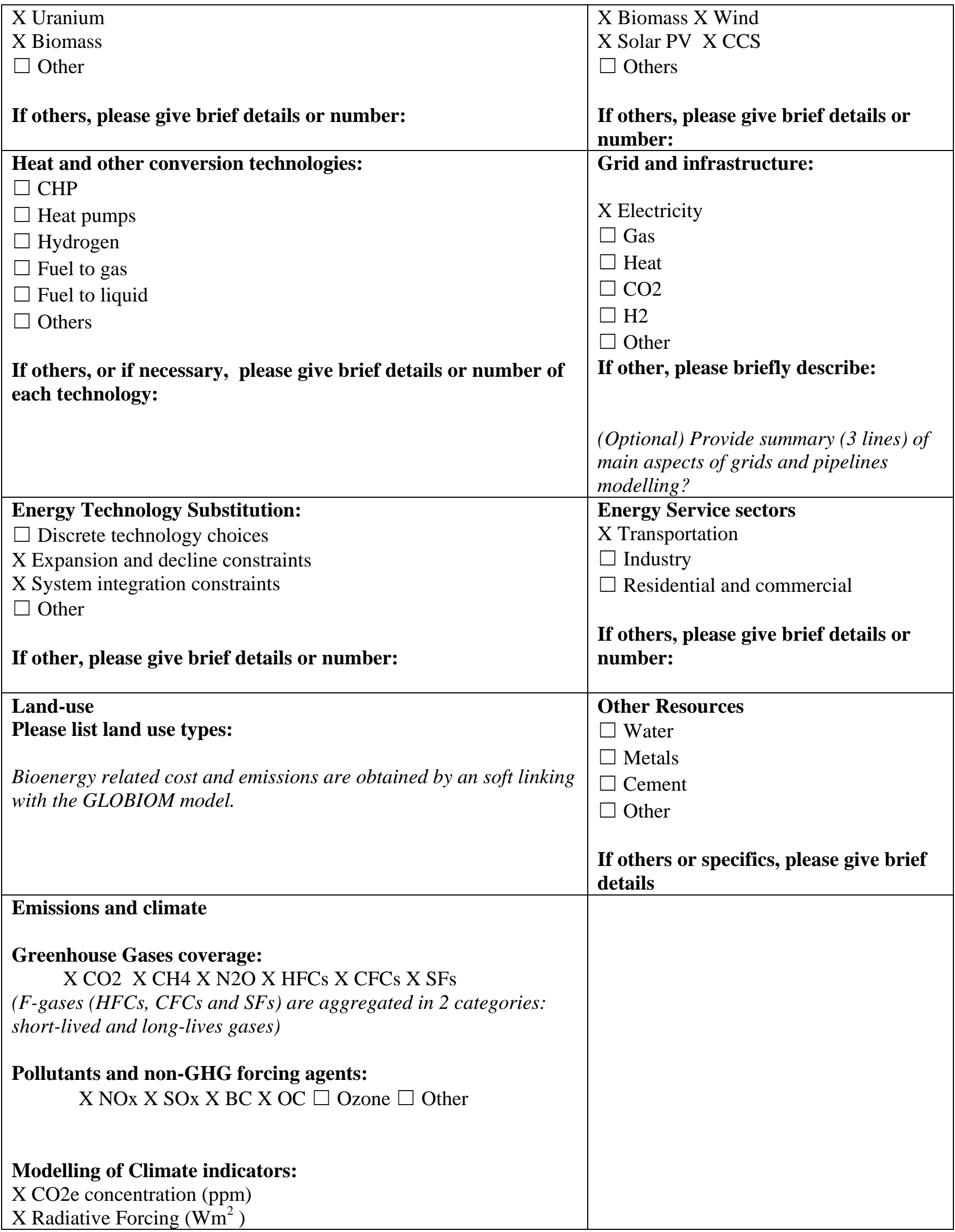


$\mathrm{X}$ Temperature change $\left(\mathrm{C}^{\mathrm{o}}\right)$

$\mathrm{X}$ Climate damages (\%GDP)

\section{Overview}

WITCH (www.witchmodel.org) consists of a dynamic global model that integrates in a unified framework the most important elements of climate change. The economy is modeled through an inter-temporal optimal growth model which captures the long term economic growth dynamics. A compact representation of the energy sector is fully integrated (hard linked) with the rest of the economy so that energy investments and resources are chosen optimally, together with the other macroeconomic variables. Land use mitigation options are available through a soft link with a land use and forestry model (GLOBIOM). A climate model (MAGICC6) is used to compute the future climate. Climate change impacts the economic output through a damage function, depending also on the rate of investments in adaptation. This allows accounting for the complete dynamic of climate change mitigation and adaptation.

WITCH represents the world in a number (currently 13) of representative native regions (or coalitions of regions); for each it generates optimal mitigation and adaptation strategies for the long term (2005 to 2100), as a result of a maximization process in which the welfare of each region (or coalition of regions) is chosen strategically and simultaneously to other regions. This makes it possible to capture regional free-riding behaviors and strategic interaction induced by the presence of global externalities. In this game-theoretic set-up, regional strategic actions interrelate through GHG emissions, dependence on exhaustible natural resources, trade of oil and carbon permits, and technological R\&D spillovers. The endogenous representations of R\&D diffusion and innovation processes constitute a distinguishing feature of WITCH, allowing todescribe how R\&D investments in energy efficiency and carbon free technologies integrate the currently available mitigation options. The model features multiple externalities, both on the climate and the innovation side. The technology externality is modelled via international spillovers of knowledge and experience across countries and time. This formulation of technical change affects both decarbonization as well as energy savings. Figure A2 provides an overview of the key features of WITCH.

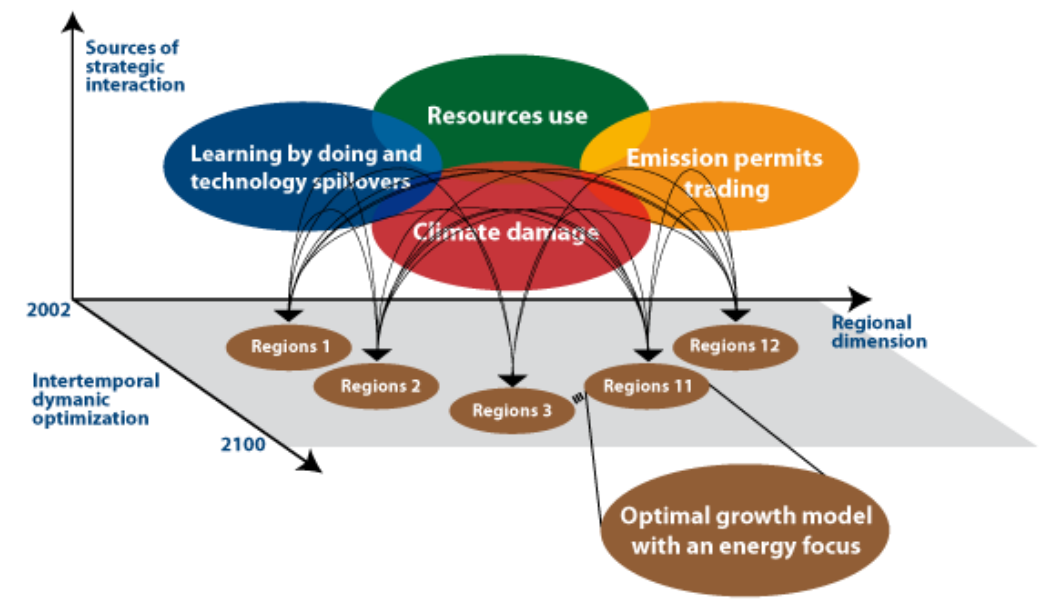

Fig. A2 Overview of the WITCH model.

Each of the model native regions solves a dynamic optimization problem with respect to the key economic, energy and climate variables. Regions interact over climate, technology and resource externalities, modeling the strategic dimension of the climate change policy problem.

\section{Modeling energy system}

In WITCH, the energy sector is fully integrated with the rest of the economy. It is distinguished in an electric sector, a transportation sector, and an aggregated non-electric (industry and residential) sectors. The energy sector is described by a production function that aggregates different factors at various levels and with associated elasticities of substitution. All the main energy carriers and technologies are included. 
Natural gas is used in the industry and residential sector as well as for generating electricity. Gas power is available with and without carbon capture and storage. WITCH also tracks methane emitted in the non-energy sector. The marginal price of natural gas, along with the other energy carriers, is determined by cumulative global extraction and available resources. Gas is traded among the 13 regions, which can buy or sell it from a common pool (e.g. bilateral trade across each region couple is not accounted for).

\section{Modeling Greenhouse gas emissions}

The model generates the greenhouse gases reported in Table A3, either directly or via exogenous assumptions. Mitigation can happen through technology substitution or storage, direct reduction via Marginal Abatement Cost Curves (MAC) or end of pipe via Emission Factors. Emissions are fed to the MAGICC6 climate model, which calculates all the climate outcome.

\section{Modeling key TEAM Technologies}

Capital costs for power plants appear directly in the capital update equations, where they translate investments in new capacity additions, which cumulate with previous depreciated capital. While part of them is influenced by learning-by-research endogenous processes in a standard WITCH setup, for this exercise all of them are enforced exogenously. Given this setting, nuclear capital costs can be input in a straightforward way. For the sake of harmonizing the models the most according to the TEAM protocol, the modelling of nuclear was further simplified by assuming constant nuclear waste management unit costs, which normally increase with world cumulated nuclear capacity

Since LCOEs are an output of the model, resulting from the assumptions on capital costs, depreciation rates, interest rates, and load factors, these are first translated in corresponding capital costs, and then input to the model. In the case of solar LCOEs, these will affect both PV and CSP capital cost, considering an extra $20 \%$ cost for the latter. The same approach is used in the case of bio-electricity non-energy costs, affecting the capital cost of both traditional and new IGCC+CCS biomass power plants. Here, the extra capital cost of the more expansive CCS plants is directly given from the CCS capital cost input. CCS capital cost is also included in the capital cost of IGCC+CCS coal plants.

Another type of parameters that appears directly in the structure of the model is the efficiency of power technologies, which translates primary energy consumed into power produced. Thus, the bio-electricity efficiency input can be accounted directly for traditional and new biomass plants. In the case of CCS energy penalty, this input affect in an inversely proportional way the original efficiencies of IGCC+CSS plants, fueled either by coal or biomass.

Finally, biofuels non-energy costs are combined additively with average unit biomass costs to determine average unit price paid for advanced biofuels. Similarly to what was done for nuclear, in this exercise the learning-byresearching and learning-by-doing dynamics, which normally determine advanced biofuels, are replaced by exogenous assumptions consistent with the sampled biofuels costs. The efficiency, as in the case of the CCS energy penalty input, is accounted multiplicatively, so that a 50\% efficiency entails a doubling of the unit price. All these inputs evolve according to the learning equation presented in the paper, where the 2005 value is chosen in consistency with the previous 2005 calibration of the model and are summarized in Table A4 below. 
Table A4: Summary of TEAM Technologies characteristics in WITCH

\begin{tabular}{lll}
\hline Technology & $\mathbf{2 0 0 5}$ value & Unit \\
\hline Bio-electricity efficiency & 19.0 & $\%$ \\
Bio-electricity non-energy cost & 0.2 & $\$ / \mathrm{KWh}$ \\
Biofuels efficiency $^{6}$ & 31.5 & $\%$ \\
Biofuels non-energy cost $_{\text {CCS additional capital cost }}$ & 10.6 & $\$ / \mathrm{GGE}$ \\
CCS energy penalty & 3781.2 & $\$ / \mathrm{KW}$ \\
Nuclear capital cost & 42.8 & $\%$ \\
Solar LCOE & 4250.9 & $\$ / \mathrm{KW}$ \\
\hline
\end{tabular}

\section{BNL Multi-region MARKAL_US model}

\section{Table A5: Summary of MARKAL_US features.}

\begin{tabular}{|c|c|}
\hline $\begin{array}{l}\text { Model Concept } \\
\text { Partial equilibrium model of U.S. energy system. The model } \\
\text { was run with elastic demands for the various energy service }\end{array}$ & $\begin{array}{l}\text { Solution Method } \\
\text { Linear optimization based on minimizing total discounted } \\
\text { energy system costs. }\end{array}$ \\
\hline & $\begin{array}{l}\text { Parametric Specification } \\
\text { System wide discount rate }=5 \%\end{array}$ \\
\hline $\begin{array}{l}\text { Markets and Trade } \\
\text { Emission permits, coal and natural gas are traded nationally. } \\
\text { Electricity includes trade with Canada and Mexico. Oil is } \\
\text { traded globally }\end{array}$ & $\begin{array}{l}\text { Model anticipation } \\
\text { Perfect Foresight }\end{array}$ \\
\hline $\begin{array}{l}\text { Model Regions: } \mathbf{1 0} \\
\text { California } \\
\text { East North Central } \\
\text { East South Central } \\
\text { Mid-Atlantic } \\
\text { Mountain } \\
\text { New England } \\
\text { Pacific } \\
\text { South-Atlantic } \\
\text { West North Central } \\
\text { West South Central }\end{array}$ & \\
\hline $\begin{array}{l}\text { Base year } \\
2010\end{array}$ & $\begin{array}{l}\text { Time horizon and step } \\
2010-2050,5 \text { years }\end{array}$ \\
\hline $\begin{array}{l}\text { Mitigation options } \\
\text { Abatement cost functions for non-CO2 GHGs } \\
\text { Decarbonization options in the energy system } \\
\text { (renewables, nuclear, biomass, ccs) }\end{array}$ & $\begin{array}{l}\text { Climate Impacts } \\
\text { Not modeled }\end{array}$ \\
\hline $\begin{array}{l}\text { Land use } \\
\text { Not modeled }\end{array}$ & $\begin{array}{l}\text { Resources considered } \\
\text { Coal, Oil, Gas, Uranium, Biomass, Carbon Storage }\end{array}$ \\
\hline $\begin{array}{l}\text { Notes } \\
\text { Full MARKAL documentation available at http://www.iea- } \\
\text { etsap.org/web/Documentation.asp }\end{array}$ & \\
\hline
\end{tabular}

\footnotetext{
${ }^{6}$ WITCH just distinguishes between traditional and advanced biofuels. For this exercise, we took the maximum value of the range for the non-fuel cost of biofuels, and associate it just to the advanced category of biofuels, being the one that is more likely subject to potentially breakthrough learning rates. Using these assumptions, resulting prices are more consistent with the usual advanced biofuel prices of the standard version of the model.
} 


\section{Introduction}

The BNL Multi-Region US MARKAL model (US MRM) is a 10 region model of the US energy system designed using the MARKet ALlocation (MARKAL) framework. MARKAL-based models are partial equilibrium models that incorporate a description of the physical energy system (Fishbone and Abilock, 1981, Hamilton et al. 1992). They are thus bottom-up models and are typically solved as cost-minimization problems. MARKAL models are currently used in around 70 countries around the world to analyze a wide array of issues such as environmental policy, energy policy, subsidy and tax regimes, efficacy of R\&D programs and associated benefits, assessment of energy efficiency programs, energy market forecasts and many more (ETSAP, 2010).

MARKAL has been developed by the Energy Technology Systems Analysis Program (ETSAP) for over 30 years. ETSAP is an Implementing Agreement of the International Energy Agency (IEA), first established in 1976. It functions as a consortium of member country teams and invited teams that actively cooperate to establish, maintain, and expand a consistent set of analytic tools.

BNL has been involved in ETSAP and the development and application of MARKAL models since the beginning in the 70s and has continually kept a set of models that have been applied to energy technology and policy issues. This document describes the latest incarnation of BNL's main US analytical tool, the BNL MultiRegion US MARKAL model (US MRM).

\section{Reference energy system}

MARKAL models represent the components of the physical energy system. At the heart of any MARKAL model is a technology database which holds the definition of a set of energy resource, conversion and end-use technologies. These energy technologies are assigned properties and attributes such as fuel consumed and produced, conversion efficiency, investment and operating costs etc.

The model structure can best be illustrated by a Reference Energy System (RES), which is a flow chart that shows how energy flows through the energy infrastructure as represented in the model. The RES thus show how the components of the energy system are linked together in a flow network where the technologies form the nodes and energy carriers represent the links (arrows). This is illustrated in Error! Reference source not found., which shows an aggregated energy system representative of most MARKAL models.

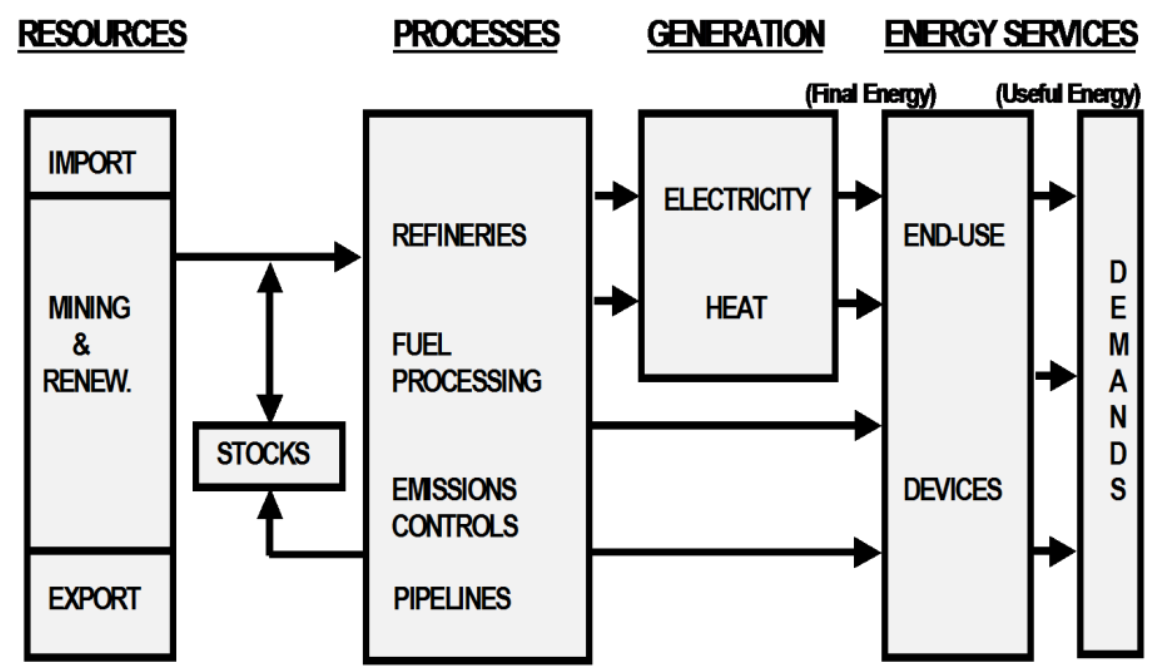

Fig. A3 Overview of the MARKAL_US Energy System 
By representing individual technologies, MARKAL provides a bottom-up approach to study the energy system. The whole energy system, from resource extraction to service demand, is included, which allows for full "wellto-wheel" comparison of technology options.

\section{Objective function}

MARKAL models are generally solved as a cost minimization problem where future states of the energy system are determined by identifying the most cost-effective pattern of resource use and technology deployment over time (Loulou et al. 2004). The MARKAL objective is thus to minimize the total cost of the system, discounted over the planning horizon. Each year, the total cost includes the following elements:

- Annualized investments in technologies;

- Fixed and variable annual Operation and Maintenance $(O \& M)$ costs of technologies;

- Cost of exogenous energy and material imports and domestic resource production (e.g., mining);

- Revenue from exogenous energy and material exports;

- Fuel and material delivery costs;

- Welfare loss resulting from reduced end-use demands.

- Taxes and subsidies associated with energy sources, technologies, and emissions.

MARKAL models are demand driven, which means that, for any feasible solution, exogenously specified energy service demands are met. The model then determines the least cost configuration of capital stock and utilization rates that will meet these demands over the full projection period. This is done while obeying a set of userdefined constraints, such as natural resource availability, technology and capital availability, environmental limitations.

The model is dynamic, meaning that the capital stock in any period is equal to the capital stock in the preceding period plus/minus any additions or retirements. The model thus keeps track of capital stock, and the solution in one period is directly linked to the solution for other periods.

Optimization is inter-temporal, which means that the optimization is performed for all periods concurrently, implicitly giving decision-makers foresight.

\section{Technology data}

Since the US MRM is a bottom-up model that individually represents thousands of energy technologies the data requirements are substantial. Costs and performance characteristics for all technologies are needed as well as information on policy, regulation, resource constraints, environmental constraints, expansion and growth constraints.

The main source of technology data for the US MRM is the EIA. Much of the relevant information is published annually as part of the AEO and the associated NEMS documentation. Other information was gathered from the residential, commercial and manufacturing energy consumption surveys, the annual coal, natural gas and petroleum annual reports, the refinery report and the electricity generator database. A range of other sources, too numerous to include here, have been consulted as well.

Like electricity prices the prices for liquid fuels are determined by the interaction of the technologies that produce them as well as the cost of the input feedstocks. Liquid fuels however, are not subject to time-of-use pricing and capacity markets which makes the price formation process less complex than for electricity. Marginal cost pricing is still used and most fuels will be priced at the crude oil price plus a cost of upgrading the crude oil (refinery margin) to the fuel in question. Alternative fuels such as corn ethanol, biodiesel or other advanced bio- and synthetic fuels are also available and will impact the pricing of marketed fuels.

\section{Modeling key TEAM Technologies}

The technologies in MARKAL that correspond to the technology classes as described in table 1, which are sensitized in terms of cost and performance parameters, include for solar power all centralized solar pv, for 
bioelectricity the biomass integrated gasification combined cycle power plants with and without carbon capture and sequestration (CCS), for nuclear the currently available light water reactors as well as the generation III/ III+ reactors and for biofuels the biomass to liquids fuel plants. Furthermore, the additional capital and energy cost sensitivity for carbon capture is also applied to coal integrated gasification combined cycle and natural gas combined cycle power plants with CCS.

In order to harmonize the input data sample with MARKAL's default input parameters all cost data for each sensitized technology had to be converted to investment cost, a total cost of investment for new capacity. Of particular interest are solar power and bio-electricity as their investment cost calculation requires factoring in the capacity factor and the charge rate for each technology; while for solar power, investment cost is also adjusted for the available investment tax credit, as currently set at $10 \%$. Nuclear power investment cost is calculated as the product of the overnight capital cost with the technology's capital interest factor. All investment costs are the regionally adjusted by a cost multiplier. For the coal and gas power plants with CCS the price premium for the carbon capture is applied on top of the investment cost of the model's corresponding baseline technology without CCS. Efficiency is a direct input for MARKAL technologies, therefore the integration of the data sample in the model only required the proportional adjustment of the carbon emission factors for each technology. Finally the CCS energy penalty was applied as an incremental efficiency penalty for all relevant technologies.

Table A6: Summary of TEAM Technologies characteristics in MARKAL_US

\begin{tabular}{lcccl}
\hline Technology & Start Year & Efficiency & Cost & Units \\
\hline Biomass to Liquids & 2015 & $69.80 \%$ & 1.297 (non-energy) & $2010 \$ / G G E$ \\
Biomass to Liquids with CCS & 2015 & $60.40 \%$ & 1.516 (non-energy) & $2010 \$ / G G E$ \\
Biomas IGCC & 2025 & $25.30 \%$ & 0.0486 (non-energy) & $2010 \$ / \mathrm{KWh}$ \\
Biomas IGCC with CCS & 2025 & $22.70 \%$ & 0.0559 (non-energy) & $2010 \$ / \mathrm{KWh}$ \\
Solar PV & 2015 & N/A & 0.294 (LCOE) & $(2010$ US) $\$ / \mathrm{KWh}$ \\
Gen III Nuclear LWR capital cost & 2020 & N/A & 1650.36 (Capital) & (2010 US) $\$ / \mathrm{KW}$ \\
\hline
\end{tabular}

\section{HIGHLIGHTS}

- Results of sensitivity analysis of energy technologies for three energy-economic models

- In-depth analysis of sign of change and key-uncertainty drivers in a multi-model context

- Report on robust findings on what uncertainty sources are key in shaping future emissions

- Use of alternative metrics for sensitivity analysis

- First integrated assessment model comparison to look at extensive sensitivity analysis of technology cost 